\title{
On Modeling Dry Deposition of Long-Lived and Chemically Reactive Species over Heterogeneous Terrain
}

\author{
G. TETZLAFF ${ }^{1}$, R. DLUGI ${ }^{2}$, K. FRIEDRICH ${ }^{3}$, G. GROSS ${ }^{4}$, \\ D. HINNEBURG ${ }^{5}$, U. PAHL ${ }^{4}$, M. ZELGER ${ }^{2}$ and N. MÖLDERS ${ }^{6 \star}$ \\ ${ }^{1}$ LIM - Institut für Meteorologie, Universität Leipzig, Stephanstraße 3, 04103 Leipzig, Germany \\ ${ }^{2}$ Arbeitsgruppe Atmosphärische Prozesse, Gernotstraße 11, 80804 München, Germany \\ ${ }^{3}$ Institut für Physik der Atmosphäre, Oberpfaffenhofen, Postfach 1116, 82230 Wessling, Germany \\ ${ }^{4}$ Institut für Meteorologie und Klimatologie, Universität Hannover, Herrenhäuser Straße 2, \\ 30419 Hannover, Germany \\ ${ }^{5}$ Institut für Troposphärenforschung, Permoser Straße 15, 04315 Leipzig, Germany \\ ${ }^{6}$ Geophysical Institute, University of Alaska Fairbanks, P.O. Box 757320, Fairbanks, \\ AK 99775-7320, U.S.A.
}

(Received: 17 November 2000; in final form: 30 July 2001)

Abstract. An explicit multi-layer subgrid-scheme was developed for a meso- $\gamma / \beta$-scale model to consider subgrid-scale surface heterogeneity, dry deposition, biogenic and anthropogenic emission of trace gases. Since dry deposition measurements of highly reactive trace species are scarce we try to evaluate this scheme by heuristic principles. The results of simulations conducted for a $5 \times 5 \mathrm{~km}^{2}$ resolution with and without this scheme are evaluated by using results of a model run with $1 \times 1$ $\mathrm{km}^{2}$ resolution, which is taken as a 'grand thruth' and which has the same resolution as the subgrid. The explict multi-layer subgrid scheme provides a similar distribution of dry deposition fluxes as the much more computationally expensive simulation with the $1 \times 1 \mathrm{~km}^{2}$ resolution.

Dry deposition fluxes determined from observations give evidence that the explicit multi-layer subgrid scheme which does not require a constant flux approximation for a layer of several decameters leads to an improvement in determining the exchange between the atmosphere and the ground.

Results of simulations with a microscale model show that the inhomogeneity at forest edges leads to an increase of the turbulent transports of up to a factor 4 compared to horizontally homogeneous terrain, which is assumed to be the conditions of the subgrid cells (and which is usually the assumption for the entire grid cell in mesoscale models). Inhomogeneity inside an extended stand of trees causes an overall increase of 5-10\% with high local extremes, i.e. such an inhomogeneity results to an underestimation of dry deposition in meso- $\gamma / \beta$-scale models. The effects are most pronounced for a wind direction perpendicular to the forest edge.

Key words: dry deposition, mesoscale modeling, microscale modeling, surface heterogeneity, forest edge, explicit multi-layer subgrid scheme.

\footnotetext{
^ Corresponding author.
} 


\section{Introduction}

In the last decades, the composition of the atmosphere has changed appreciably by anthropogenic emissions of a wide variety of trace species. In the urban atmosphere, high concentrations of these so-called primary pollutants can be found. However, concurrent processes of transport and transformation of trace species lead to polluted air also in rural areas where high concentrations of so-called secondary pollutants like photochemical oxidants can be observed. Dry deposition is an important sink for many of these trace gases and represents a burden on the vegetation-soil and natural water systems. To quantify the atmospheric input of highly reactive oxidants and acidic compounds into such ecosystems, chemistry transport models (CTMs) of various degrees of complexity have been developed and applied (e.g., Chang et al., 1987; Venkatram et al., 1988; Ebel et al., 1994; Kramm et al., 1994; Vogel et al., 1995; Padro et al., 1995). Recent results from aircraft measurements as well as theoretical and numerical modeling studies showed that landscape heterogeneity may affect the fluxes of water, energy (e.g., Avissar and Pielke, 1989; Seth et al., 1994; Mahrt et al., 1995; Mölders et al., 1996) and trace species (e.g., Kramm et al., 1994, 1996; Ganzeveld and Lelieveld, 1995) and, hence, cloud formation as well as wet and dry deposition. Unfortunately, the horizontal and vertical grid resolution of CTMs is much coarser than that required by dynamic-chemical studies. Moreover, a grid cell of a mesoscale ${ }^{\star}$ numerical model encompasses several square kilometers for which the dominant land-use type is usually taken to be a representative one to determine the water, energy and trace gas fluxes at the surface (Kramm and Mölders, 1996). Natural surfaces, however, are heterogeneous over virtually all scales, i.e., also over the resolvable scales considered in meso- $\gamma / \beta$-scale or microscale models. Since these models have to estimate the energy, water and trace gas fluxes at scales ranging from several acres to square kilometers, the subgrid-scale heterogeneity generally has to be parameterized. Three major subgrid effects may play an important role on the meso- $\gamma / \beta$-scale: ${ }^{\star \star}(1)$ the subgrid-scale heterogeneity of the landscape at both the micro- and mesoscale, (2) the subgrid-scale heterogeneity of natural and anthropogenic emission sources, and (3) chemical reactions among trace species when determining dry deposition fluxes (Kramm and Mölders, 1996). Zooming into the microscale, ${ }^{\ddagger}$ in an area with forests, the following additional aspects may become

\footnotetext{
* Mesoscale can be descriptively defined as having a horizontal spatial and temporal scale smaller than the conventional rawinsonde network, but significantly larger than individual cumulus clouds. The typical horizontal scale amounts to a few kilometers to several hundred kilometers or so, with a time scale of $1 \mathrm{~h}$ to $3 \mathrm{~d}$ (e.g., Orlanski 1975).

$\star \star$ Scales of motion in which vertical accelerations become important can be referred to as meso$\gamma$-scale. The associated temporal and spatial scales are about $0.5 \mathrm{~h}$ to $0.5 \mathrm{~d}$ and $2 \mathrm{~km}$ to $20 \mathrm{~km}$, respectively. The meso- $\beta$-scale refers to temporal and spatial phenomena of about several hours to 1 day and $20 \mathrm{~km}$ to $200 \mathrm{~km}$ in extension (Orlanski, 1975).

$\$$ Microscale here refers to phenomena of temporal and spatial scales of seconds to $0.5 \mathrm{~h}$ and several meters to several hundred meters.
} 
evident: (1) leaf area density of the foliage, (2) edge lengths, (3) inhomogeneous heights of stand, and (4) the turbulent state within the forest canopy (Pahl, 2000).

Efficient tools to determine the exchange of energy and water fluxes as well as chemically conserved trace species between the atmosphere and the ground (soil, vegetation, etc.) are single-layer (e.g., Deardorff, 1978; Hicks et al., 1987) and multi-layer SVAT (soil vegetation atmosphere transfer) models (e.g., Yamada, 1982; Meyers and Paw U, 1986, 1987; Baldocchi, 1988; Meyers and Baldocchi, 1988; Shaw and Schumann, 1992; Inclan et al., 1996; Ziemann, 1998). Recently, various SVAT-models to determine dry deposition and biogenic emissions of highly reactive trace species over low vegetation were developed by Kramm et al. (1994, 1996). Some of these single- and multi-layer SVAT-models use Deardorff's (1978) mixture approach on the microscale (e.g., Kramm et al. 1994, 1996; Ziemann, 1998).

In mesoscale models, single-layer SVAT-models assuming horizontally homogeneous conditions for each grid cell are customarily applied. Thus, they cannot be used, for instance, to study the effects generated by forest edges or individual trees. To consider subgrid-scale heterogeneity of a landscape, dry deposition fluxes as well as biogenic and anthropogenic emission fluxes, an explicit multi-layer subgrid scheme as first suggested by Tetzlaff and Mölders (1997) is introduced into the meso- $\gamma / \beta$-scale model GESIMA (Geesthacht's simulation model of the atmosphere; Kapitza and Eppel, 1992; Eppel et al., 1995), denoted hereafter as GESIMA_EMS (GESIMA with explicit multi-layer subgrid scheme). Herein, the horizontal and vertical resolution is finer in the near-surface layer, and within the soil, whereas the remaining model domain is unchanged (see Figure 1). Note that an overview on possible other methods is also given in Tetzlaff and Mölders (1997). It is evident that determining the concentrations of any gaseous species in the atmosphere requires consideration of the trace gas cycle from emission through chemical transformation during transport finally to deposition, as well as its complicated interrelations with the energy and water cycles (e.g., Seinfeld, 1986; Kramm and Mölders, 1996). Since chemical reactions, which permanently change the composition of the atmosphere, and transport processes act concurrently, modeling of these concurrent processes demands a lot of CPU-time when such dynamic-chemical systems are numerically simulated by CTMs of adequate grid resolution. Introducing an explicit multi-layer subgrid scheme is, therefore, highly desirable to realize reasonable CPU-time consumption. As compared to conventional nesting (e.g., Pleim et al., 1991; Feldmann et al., 1996) or multi-scale methods (e.g., Kumar et al., 1994) the main advantage of an explicit multi-layer subgrid scheme is that a finer resolution is kept only in those regions of the model domain where dynamic-chemical interrelations between the atmosphere at the ground demands it to guarantee numerical treatment with a sufficient degree of accuracy. For the remaining model domain, i.e. the upper model-layers, a coarser grid resolution is suitable (Figure 1). Another important advantage of this scheme is that subgrid scale surface heterogeneity can be considered closer to its 


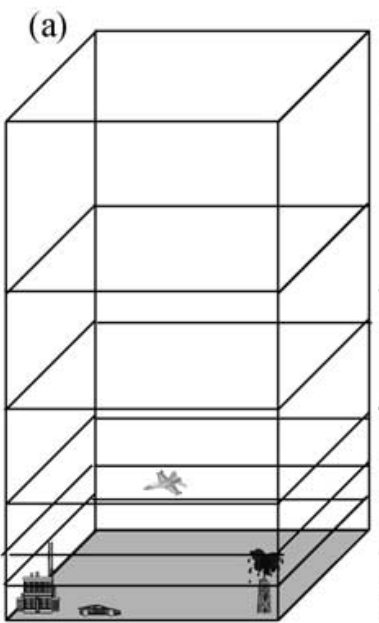

(b)

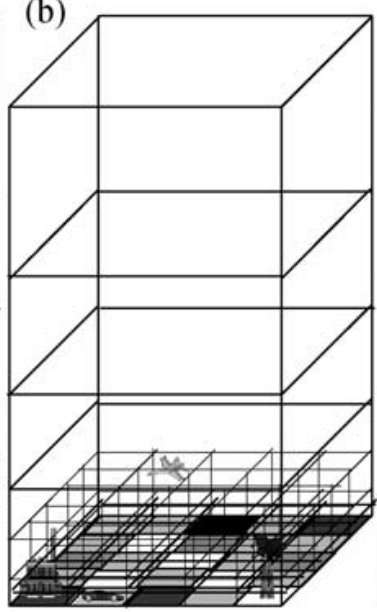

(c)

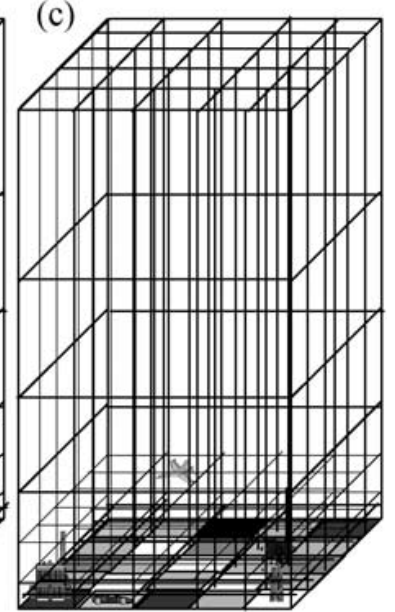

Figure 1. Schematic view of an atmospheric grid column in a CTM using (a) the commonly applied constant flux approach for a layer of several decameters and the strategy of dominant land-use (e.g., HOM5 in Subsection 3.1), (b) an explicit multi-layer subgrid scheme which divides the grid cell of the model into several subgrid cells by introducing several vertical layers into the surface layer and breaking the horizontal direction into smaller patches of different land-use to catch horizontal variability of land-use, soil-type, biogenic and antropogenic emissions, trace gases, chemical reactions as well as dry deposition, and to consider vertical variations in trace gases, chemical reactions and anthropogenic emissions (e.g., EMS5 in Subsection 3.1), and (c) a finer resolved grid which is computationally more expensive and time-consumable (e.g., HOM1 in Subsection 3.1).

natural equivalent (Tetzlaff and Mölders, 1997), i.e., the horizontal and vertical variations in trace gas concentration and fluxes can be resolved finer than in the approaches commonly applied in chemistry transport modeling (e.g., Figure 1). Furthermore, the increased resolution in the near-surface layer avoids the standard constant flux approach with which the dry deposition fluxes also of highly reactive trace species are customarily determined (e.g., Walcek et al., 1986; Wesely, 1989). As demonstrated by theoretical considerations, observations and/or model studies (e.g., Fitzjarrald and Lenschow, 1983; Lenschow and Delany, 1987; Brost et al., 1988; Kramm, 1989; Gao et al., 1991; Kramm and Dlugi, 1994; Kramm et al., 1995; Padro et al., 1995; Spindler et al., 1996) the constant flux approximation on which the resistance approach is based seems to be acceptable only for chemically conservative species or for thin layers like the sublayer close to the surface for which the characteristic response times of diffusive transfer and chemical processes differ considerably (Dlugi, 1993; Kramm and Dlugi, 1994).

Hanson and Lindberg (1991) as well as Kramm (1995) summarized dry deposition data for several nitrogen compounds for vegetated and non-vegetated sites. As shown by these authors, most of these data are based on enclosure and micrometeorological techniques where the former are only representative for a spot of up to a 
square meter and the latter, of course, for areas of several hectares (e.g., Businger, 1986). Thus, only micrometeorological measurements are able to provide flux data that can be used for model evaluation. Unfortunately, most micrometeorological techniques are so-called indirect methods (e.g., Bowen-ratio and aerodynamic profile techniques, inferential methods etc.) which are often based on the same conditions of turbulent closure than conventional CTMs. Recently, the relaxed eddy accumulation (REA) method was tested by Oncley et al. (1993) using carbon dioxide and has been successfully used for measurements of biogenic hydrocarbon fluxes (e.g., Bowling et al., 1999). The interpretation of these data, however, again requires model assumptions which have to be evaluated (e.g., Kramm et al., 1999). Rinne et al. (2000) carried out disjunct true eddy accumulation (DEA) flux measurements for $\alpha$-pinene fluxes. For a direct model evaluation, however, results of dry deposition fluxes directly measured by eddy covariance or true conditional sampling (often called eddy accumulation) techniques are more appropriate. Since many trace constituents cannot be measured fast enough to apply eddy covariance techniques, the conditional sampling method that does not require fast-response chemical sensors seems to be an alternative. However, as argued by Kramm et al. (1999), considerable efforts have to be undertaken to develop a conditional sampling system for measuring eddy fluxes of trace species under field conditions, and, therefore, an adequate conditional sampling system is still required. Thus, directly measured dry deposition fluxes of highly reactive trace gases exist only for a few trace species and these flux data are still scarce. Consequently, for most trace species directly measured flux data are unavailable for model evaluation (e.g., Kramm et al., 1999). In recognition of all these short-comings in model evaluation, we try to evaluate GESIMA_EMS by considering heuristic principles.

In a first step, the improvements achieved by using GESIMA_EMS are evaluated by results obtained from a GESIMA run with high resolution $\left(1 \times 1 \mathrm{~km}^{2}\right)$. Since direct measurements of dry deposition fluxes over limited forest areas do not exist, the three dimensional microscale model, TreeMo-3D, was improved and applied (e.g., Gross, 1993; Pahl, 2000) to support the results provided by GESIMA_EMS. TreeMo-3D is able to generate the realistic features of a turbulent flow around and above a limited forest area (e.g., Pahl, 2000). Thus, it serves to address the effects of trees and forest edges on turbulent mixing, and in a further step, on the enhancement or weakening of dry deposition of trace species. Moreover, as demonstrated later, potential measurements inside a forest may strongly be affected by where they are carried out. Therefore, results from a field study performed over horizontally homogeneous low vegetation are used to elucidate the role of chemical reactions. In doing so, the dry deposition fluxes are first determined with consideration of chemical reactions like in the explicit multi-layer subgrid scheme and alternatively like in conventional algorithms of CTMs (e.g., Baer and Nester, 1992; Hass et al., 1995). 


\section{Brief Description of the Models and the Measurements}

For both the models, the governing equations for a turbulent flow of a nonhydrostatic atmosphere are the Boussinesq-approximated equations of motion, the first law of thermodynamics, the balance equations for trace species, and the equation of continuity for an anelastic medium (GESIMA_EMS) and incompressible medium (TreeMo-3D), respectively. The reference state is assumed to be hydrostatic. The turbulent fluxes, introduced by Reynolds decomposition and averaging, are parameterized by flux-gradient relationships with exception of the lowest subgrid layer where the surface stress and the near-surface fluxes of heat and water vapor as well as trace species are expressed by bulk transfer approaches using the non-dimensional drag coefficient and the respective bulk transfer coefficients (e.g., Arya, 1988). To determine the Reynolds stress tensor as well as the turbulent fluxes of heat, water vapor, and trace species above the near-surface layer, a one-and-a-half-order closure scheme of level 2.5 in the hierarchy of Mellor and Yamada (1974) is considered. Here, the elements of the eddy diffusivity tensor are approximated by only two types of elements, namely by vertical and horizontal eddy diffusivities where the latter are assumed to be proportional to the former. The vertical eddy diffusivity of momentum, $\mathbf{K}_{m, v}$, is derived from the solution of the balance equation for the turbulent kinetic energy (TKE) by introducing the Kolmogorov-Prandtl relation and the mixing length according to Blackadar's (1962) approach slightly modified by Mellor and Yamada (1974). To calculate the vertical eddy diffusivities for heat, $\mathrm{K}_{h, v}$, and matter, $\mathbf{K}_{q, v}$, the vertical eddy diffusivity for momentum, the turbulent Prandtl number, $\operatorname{Pr}_{t}=\mathrm{K}_{m, v} / \mathrm{K}_{h, v}$, and the turbulent Schmidt numbers for water vapor and trace species, $\mathrm{Sc}_{t, q}=\mathrm{K}_{m, v} / \mathrm{K}_{q, v}$, are used (see also Mölders et al., 1996). These characteristic numbers are considered to be functions of the thermal stratification. They were derived from the local stability functions of Businger et al. (1971) and the assumption that $\mathrm{Sc}_{t, q}=\operatorname{Pr}_{t}$. For the discrete representation of model variables staggered grids of Arakawa-C type are applied in both numerical models (Kapitza and Eppel, 1992; Pahl, 2000), where GESIMA_EMS uses a terrain-following coordinate system. In both models, chemical reactions, turbulence, and transport are calculated on their characteristic time scales.

\subsection{THE MESO- $\gamma / \beta$-SCALE MODEL}

The model physics of GESIMA_EMS differs from the conventional GESIMA (Eppel et al., 1995) by: (1) the inclusion of an explicit multi-layer subgrid-scheme to consider subgrid-scale heterogeneity of precipitation, biogenic and anthropogenic emissions, and dry deposition fluxes as well as subgrid-scale surface heterogeneity in a finer resolution than that of the remaining model (e.g., Mölders et al., 1996; Hinneburg and Mölders, 1999, 2000; Hinneburg, 2001); (2) the inclusion of trace gas transport as well as chemical transformation (e.g., Hinneburg and Mölders, 1999, 2000; Hinneburg, 2001); (3) the determination of the surface stress and near- 
surface fluxes of heat and water vapor as well as trace gases by use of Kramm et al.'s (1995) parametric model to calculate the non-dimensional drag coefficient and the bulk transfer coefficients of heat and matter; (4) the treatment of cloud microphysics by a five-water-class bulk-parameterization scheme which includes water-vapor, cloud water, rainwater, ice and graupel (e.g., Mölders et al., 1997); and (5) the modifications of the SVAT model (see Mölders, 1998). Furthermore, the stomatal resistances of the canopy against water loss and trace gas uptake are taken into account (e.g., Mölders, 1998). Six different vegetation types are considered, namely, grassland, cropland, heath, deciduous forest, mixed forest, and coniferous forest, respectively. In addition, dense and loose settlements, waters, and bare soil are taken into account.

The subgrid scheme of Mölders et al. (1996) was vertically extended by introducing additional levels (here 10, but up to 50 are possible) within the lowest model layers. As aforementioned, this subgrid with finer horizontal and vertical resolution allows consideration of the anthropogenic emissions closer to their real location within the grid-cell of the coarse grid (see Figure 1). Thus, the subgrid heterogeneity of emission and, hence, concentration distributions can be considered closer to the situation in nature (Figure 1). Furthermore, this explicit multi-layer subgrid also overcomes the constant flux assumption for a layer of several meters thickness and accounts for chemical reactions down to the viscous sublayer. The lowest model level of GESIMA is $20 \mathrm{~m}$. This layer is divided into 10 sublayers so that the outer edge of the first sublayer is located about $0.5 \mathrm{~m}$ above ground. The adjacent two layers above are also divided horizontally (e.g., Figure 1). As argued by Dlugi (1993), Kramm and Dlugi (1994) as well as Kramm et al. (1994), the constant flux approximation seems to be suitable to describe the diffusive transfer also of chemically high-reactive trace gases across such a thin sublayer. Under the conditions described a resistance network analogy is applied to determine dry deposition fluxes. In all subgrid layers as well as in all layers above, chemical reactions may occur among the trace gases existing in those sublayers and layers, respectively. Since anthropogenic emissions of trace gases are released into the sublayer and into the subgrid area of their real emission height and horizontal location within the grid cell (see Figure 1), the trace gas distribution can be described closer to the situation in nature from the very beginning of the model run. In contrast to the common treatment in CTMs, in the explicit multi-layer subgrid scheme, the individual grid cells of the surface-layer are composed of several smaller subgrid-cells that all have their own trace gas concentrations, chemical reactions, and transport as well as their own emissions if any (see Figure 1). At the surface, the horizontal heterogeneity of deposition and biogenic emissions is higher resolved when the explicit multi-layer subgrid scheme is used than in the case of a strategy of dominant land-use, i.e. the subgrid-scale heterogeneity of sources and sinks is considered. All in all, this means that, within the first layers above ground, trace gases are distributed inhomogenously with respect to both space and concentration. Note that, in CTMs, usually trace gases are assumed to be 
instantaneously distributed homogeneously within the entire grid cell immediately after their emission (e.g., Chang et al., 1987; Venkatram et al., 1988). Recently, Kramm and Meixner (2000) showed that the intensity of segregation generated by the turbulent flow may appreciably reduce the efficiency of chemical reactions and, hence, modifies the grid cell averaged concentrations. Since the results from field and modeling studies show that dry deposition fluxes of nitrogen compounds can already be affected by chemical reactions on a vertical scale of $5 \mathrm{~m}$ to $15 \mathrm{~m}$, using an explicit multi-layer subgrid scheme and calculating chemical reactions in each subgrid cell of each sublayer better represents the strongly changing flux profiles and distributions of trace gases in the immediate vicinity of sinks and sources.

As pointed out above, dry deposition and biogenic emissions strongly depend on the under-lying soil surface and vegetation. Thus, the bulk-stomatal resistance of vegetation types against water loss and trace gas uptake is calculated for each subgrid cell using its individual land-use type. Therefore, it has to be assumed that the dry deposition and emission processes can be simulated closer to their natural equivalent by applying the explicit multi-layer subgrid scheme rather than by assuming only one homogeneous vegetation type for the entire grid-cell as still done in chemistry transport modeling (see Figure 1). In the case of the strategy of dominant land-use type, dry deposition may be over- or underestimated depending on the respective combination of land-use types within the grid cell because the various land-use- and soil-types take up trace gases differently (e.g., Ganzeveld and Lelieveld, 1995).

The numerical methods used in GESIMA are described in detail by Kapitza and Eppel (1992) so that only a brief description of these procedures is given here for completeness. The prognostic model equations are solved with a predictor/corrector scheme. The advection of momentum and sensible heat is treated with a modified MacCormack scheme, whereas the advection of the aforementioned trace constituents is dealt with by the positive definite Smolarkiewicz scheme (Smolarkiewicz, 1984; Smolarkiewicz and Clark, 1986). The horizontal diffusion is computed by applying an explicit scheme. Vertical diffusion is calculated implicitly. Also Coriolis terms are treated implicitly.

At the top of the model, a rigid lid together with a sponge layer to absorb vertically propagating gravity waves, are used. At the lateral boundaries, the Orlanski (1976) radiation-boundary condition is applied for the normal component of momentum, and a zero-gradient method is used for all other variables (water vapor, cloud water, rainwater, ice, graupel, temperature, trace species, etc.).

A reduced version of the reaction mechanism described by Kramm (1995) which is based on the reaction kinetic model by Falls and Seinfeld (1978) for photochemical smog and the slightly modified versions of the reaction kinetic models by McRae and Seinfeld (1983) as well as McRae and Russel (1984) is applied (see Hinneburg, 2001).

The emission scenario of the gases was provided by Wickert (1997, pers. com.) in a spatial resolution of $1 \times 1 \mathrm{~km}^{2}$ and a temporal resolution of 1 hour. It is based 
on yearly sums of emitted components of various trace species and particles from both point and area sources. Wickert interpolated the data depending on synoptic situation, time and location (for more details see e.g., Müller, 1994; Obermeier, 1995; John, 1999). It is known that sometimes the ground may be regarded as a source for $\mathrm{NO}$ and $\mathrm{NO}_{2}$ (e.g., Slemr and Seiler, 1984) and it has been shown by numerical studies that concentration fluxes may significantly be affected by such emissions from the soil (e.g., Kramm et al., 1995, 1996). Therefore, the exhalation of $\mathrm{NO}$ and $\mathrm{NO}_{2}$ from soil is taken into account by the so-called Kramm- $\mu$-factors ( $\mu<1$ deposition, $\mu=1$ compensation, $\mu>1$ emission of $\mathrm{NO}$ and $\mathrm{NO}_{2}$ ) which are expressed as empirical functions of time in accord with Kramm et al. (1994, 1995). In the GESIMA simulations using the $5 \times 5 \mathrm{~km}^{2}$ resolution without the explicit multi-layer subgrid scheme, the mean anthropogenic and biogenic emissions occurring within a $5 \times 5 \mathrm{~km}^{2}$ grid-cell are assumed to represent the emission conditions.

The model domain extends $100 \mathrm{~km}$ in a east-west direction and $70 \mathrm{~km}$ in a south-north direction (see Figure 2). The vertical resolution varies from $20 \mathrm{~m}$ near the ground to $1 \mathrm{~km}$ at a height of $10 \mathrm{~km}$. Above and below a height of $2 \mathrm{~km}$ there are 8 levels. The horizontal grid-spacing is $5 \times 5 \mathrm{~km}^{2}$ for the atmospheric grid-cells. Within the framework of the explicit subgrid scheme, each atmospheric grid-cell falls into 25 subgrid-cells of $1 \times 1 \mathrm{~km}^{2}$ each at the earth-atmosphere boundary and within the soil. In the reference simulation denoted to as the 'grand truth', the horizontal grid-spacing is $1 \times 1 \mathrm{~km}^{2}$ for the atmospheric grid-cells, vertical resolution of the surface layer is the same as the vertical resolution of the multilayer subgrid and no explicit horizontal subgrid is applied.

\subsection{THE MICROSCALE MODEL}

The microscale model TreeMo-3D (Pahl, 2000) is suitable for considering the effects of obstacles of different porosity on the distribution of the different meteorological variables and trace species. By introducing a drag term in the equations of motion and TKE which is generated by the vegetation elements, the reduction of mean wind speed can be simulated while turbulence increases simultaneously. As the mixing length is often restricted within the forest canopy by vegetation elements, a mixing length approach according to Inoue (1963) as well as Meyers and Paw U (1986) is applied for this layer when such a restriction occurs. With the knowledge of mean wind and turbulence, the dry deposition fluxes of atmospheric tracers on vegetation elements and on the earth's surface can be estimated by introducing a deposition velocity $v_{D}$, which implies that the constant flux approximation is applied. Here, this approximation can be assumed to be valid for calculating the dry deposition fluxes because the lowest model layer is only $1 \mathrm{~m}$ thick. In such a thin layer, the vertical variation of concentration are usually small. The quantity $v_{D}$ depends on the turbulent state in the lower part of the atmosphere, and is strongly affected by the characteristics of the surface and canopy. 


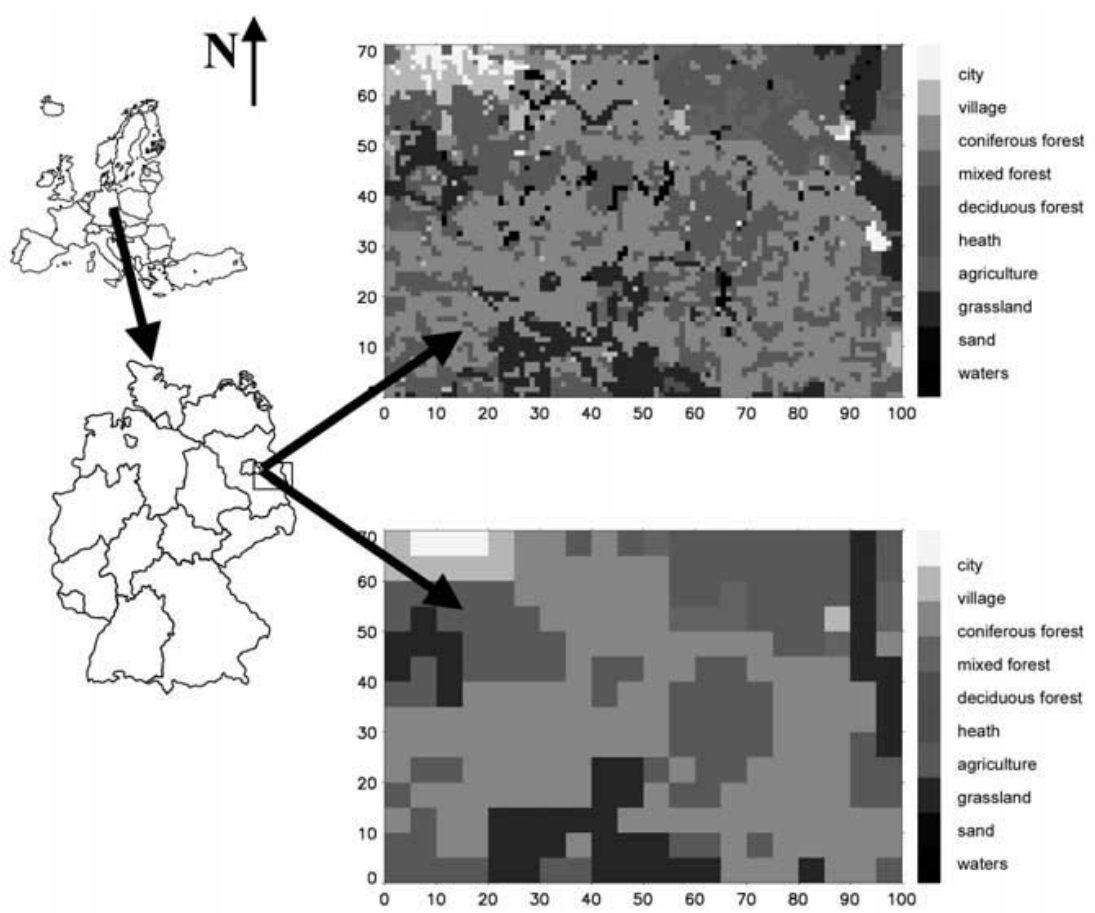

Figure 2. Location of the model domain within Europe and Germany as well as distribution of land-use in the resolution of the fine grid and the subgrid as used in HOM1 and EMS5 (upper part), as well as in the coarse resolution applying the strategy of dominant land-use type as applied in HOM5 (lower part). The zero point of the coordinate system is located at $13^{\circ} 16^{\prime} \mathrm{E}, 51^{\circ} 52^{\prime} \mathrm{N}$, and the horizontal extension amounts to $70 \mathrm{~km}$ in south-north direction and $100 \mathrm{~km}$ in west-east direction. Note that the strategy of dominant land-use type assumes that the land-use dominating in a grid cell can be regarded as the representative one to calculate the energy-, water-, deposition- and emission fluxes.

In TreeMo-3D, the Adams-Bashforth scheme is applied for the time integration of the prognostic model equations. Centered difference approximations are used in space except for the advection terms where a Smolarkiewicz (1984) scheme is also adopted (see also Smolarkiewicz and Clark, 1986).

At the upper boundary, all quantities correspond to their respective mesoscale values. At the lateral boundaries, a zero-gradient flux is assumed for all quantities except for momentum. Here, a constant flux is assumed for inflow.

TreeMo-3D is coupled with the a modified version of Stockwell et al.'s (1990) chemical reaction mechanism (for more details see, e.g., Trepte, 1998).

Since there are usually no anthropogenic emissions in forests typical background concentrations are assumed for all constituents. A 1D-simulation serves to gain vertical profiles consistent with meteorological conditions. 
In order to resolve the large variations of the meteorological variables and trace species in and around the porous tree obstacles a high spatial resolution is required. Therefore, in the horizontal directions, a grid width ranging from $1 \mathrm{~m}$ to $5 \mathrm{~m}$ is applied while, in the vertical direction, the grid layers within the lowest $30 \mathrm{~m}$ of the atmosphere increase from $1 \mathrm{~m}$ above ground to $2 \mathrm{~m}$ at a height of $30 \mathrm{~m}$.

\subsection{BRIEF DESCRIPTION OF SITE, OBSERVATIONS AND EXPERIMENTAL DESIGN}

In the times from 26 August to 10 September 1991 and 6 September to 26 September 1993, the SANA field experiments were carried out close to the village of Melpitz near Torgau/Saxony. This site is located in nearly flat terrain covered by low vegetation like grass (for a detailed site description see, e.g., Spindler et al., 1996; Seiler et al., 1996). During the field experiments, besides the meteorological quantities (e.g., wind, temperature, humidity, fluxes of momentum, sensible and latent heat, pressure, precipitation, radiation, etc.) trace gases and dry deposition fluxes of $\mathrm{SO}_{2}, \mathrm{O}_{3}, \mathrm{NO}_{2}, \mathrm{NO}, \mathrm{NH}_{3}, \mathrm{HNO}_{3}, \mathrm{NH}_{4} \mathrm{NO}_{3}$, and other compounds were determined. The fluxes of momentum, sensible and latent heat as well as of some long-lived and chemically reactive trace gases $\left(\mathrm{CO}_{2}, \mathrm{SO}_{2}, \mathrm{O}_{3}, \mathrm{NO}_{2}, \mathrm{NO}\right)$ were also measured by eddy covariance techniques at two or three heights between $3 \mathrm{~m}$ to $15 \mathrm{~m}$ above ground (e.g., Beier et al., 1997). Alternatively, these quantities were also determined by aerodynamic profile and modified Bowen-ratio techniques as described, for instance, by Dlugi (1988), Kramm (1989), and Müller et al. (1993). Table I gives a brief overview on the instrumentation (further details see also Seiler et al., 1996; Brunemann et al., 1996; Beier et al., 1997).

Since many different processes (e.g., transport, turbulence, evapotranspiration, sorption, desorption, biogenic activity, emission, chemical reactions, etc.) are involved in dry deposition, it is necessary to classify measured data into possible deposition scenarios of different dominance of the processes as a basis to evaluate models. The chemical reactions occurring during the atmospheric transport as a part of the dry deposition process, among other things, depend on radiation, air temperature, and humidity, for which, for instance, days of low and high insolation have to be distinguished. To obtain a greater data basis of various synoptic, hydrologic, and chemical conditions for evaluation of parameterizations or models the data have to be joined from different campaigns. The data gained from the two SANA-experiments in 1991 and 1993 are classified according to these above mentioned criteria, i.e., dominance of transport, turbulence, plant-physiology, biogenic activity, emission, chemical reactions, hydrological and thermodynamic conditions, etc.

In our study, the data analysis is focussed on (1) the derivation of heightinvariant fluxes by using the constant flux approximation, (2) consideration of chemical reactions among trace species during the diffusive transfer across the turbulent near-surface layer, and (3) the investigation of the influence of the hydro- 


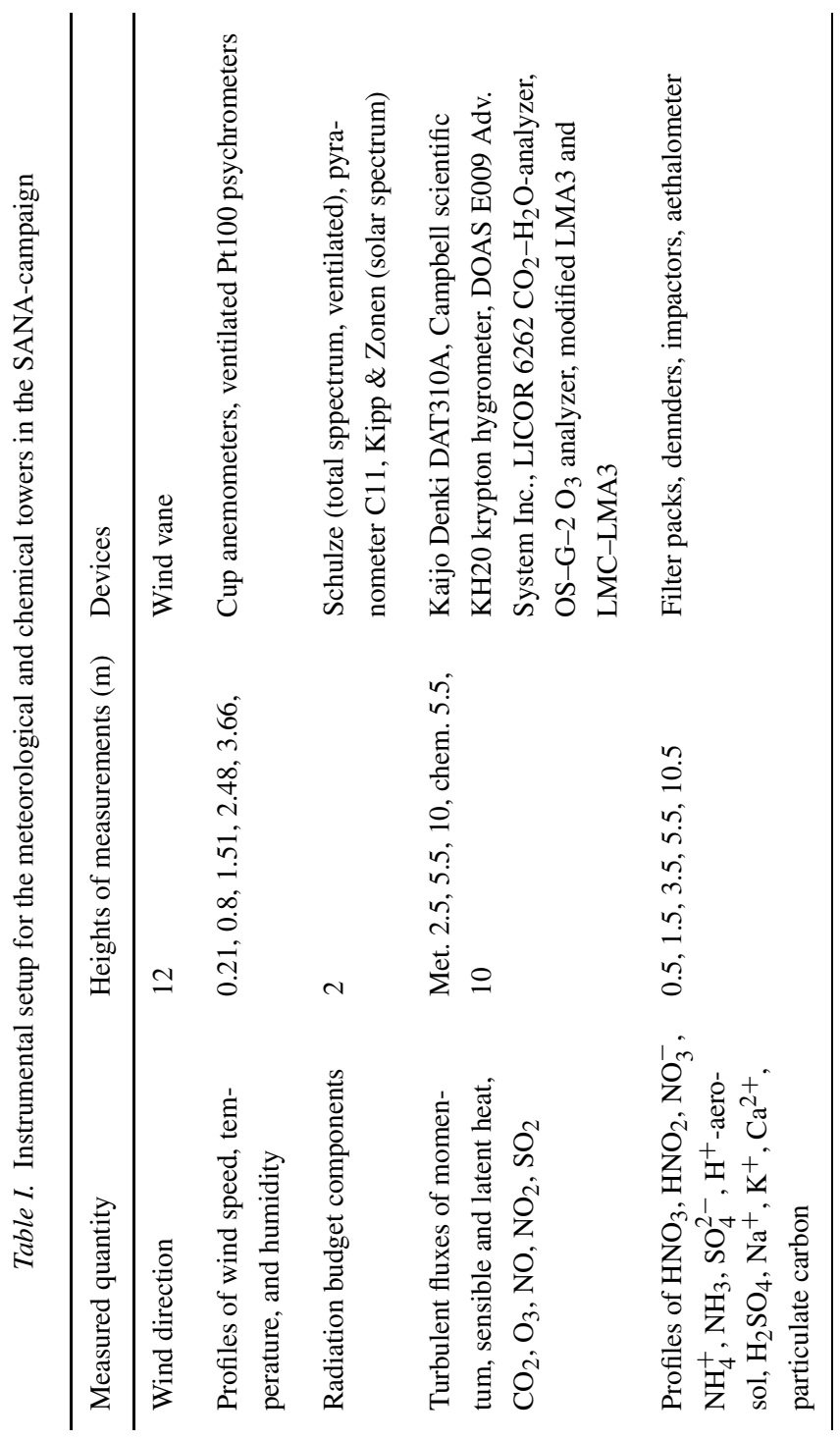


logical cycle on fluxes and uptake of chemically reactive trace gases by vegetation and soil. Two synoptic situations, which will be described in more detail later in this subsection, serve as examples to characterize the complexity of the transport of reacting species. In doing so, an analysis of the chemical interrelation between nitrogen compounds is presented to evaluate simulated fluxes and concentrations of $\mathrm{NO}, \mathrm{NO}_{2}, \mathrm{HNO}_{3}, \mathrm{NH}_{3}, \mathrm{NH}_{4}^{+}, \mathrm{HNO}_{2}$, and total nitrogen.

Comparison of the results obtained by eddy covariance, aerodynamic profile and modified Bowen-ratio techniques allows calculation of the flux divergence for reactive compounds $\left(\mathrm{O}_{3}, \mathrm{NO}, \mathrm{NO}_{2}\right)$ under conditions where the chemically conserved trace species (e.g., Kramm et al., 1994, 1995) fulfill the criteria of a constant flux approximation when advection effects are of minor importance, and, hence, negligible (e.g., Beier et al., 1997). As described by Kramm and Dlugi (1994), the vertical fluxes of $\mathrm{NH}_{3}, \mathrm{HNO}_{3}$, nitrate, and ammonium are calculated from exchange coefficients of heat, water vapor, carbon dioxide, ozone, and momentum as well as the vertical concentration profiles of sets of the nitrogen species whose total concentration is conserved and, in a further step, for the vertical concentration profiles of each 'individual' trace constituent considered as chemically reactive. If the vertical flux profiles of the sets of compounds fulfill the constant flux criteria in a micrometeorological sense (i.e., the fluxes of chemically conserved species as well as heat, and momentum may vary not more than 10 percent of their near-surface magnitudes) any flux divergence obtained for each 'individual' trace constituent can be classified to be generated by chemical reactions.

With respect to the weather situations the two cases, discussed here as examples, were similar in many respects, however, they differed concerning hydrological and chemical conditions. The major features may be described as follows: During the 1991 campaign, the soil was dry, and the air temperature generally did exceed a daily maximum of $20^{\circ} \mathrm{C}$. Emission fluxes of $\mathrm{NO}$ and $\mathrm{NH}_{3}$ were observed during the late morning hours until the afternoon when dew evaporation occurred in the morning. Temperatures rising above about $14{ }^{\circ} \mathrm{C}$ were accompanied by a decrease of the relative humidity and caused ammonium nitrate dissociation from about late morning right into the afternoon (see also Seidl et al., 1996). During the measuring period of fall 1993, air temperature was lower than in fall 1991. The relative humidity was higher than 60\%, while in September 1991, it was below 60\% during the late morning to late afternoon. These different hydrometeorological conditions also lead to a different behavior of dry deposition and biogenic emissions. Thus, for airborne and deposited particles, the chemical reactions of the $\mathrm{NH}_{3}-\mathrm{NH}_{4}^{+}-$ $\mathrm{HNO}_{3}-\mathrm{NO}_{3}^{+}$-system were limited by thermodynamic conditions (e.g., Clegg et al., 1998), and, consequently the corresponding individual constituents were nearly conserved during most days of the 1993 campaign. A more detailed description of the synoptic regimes can be found in Seiler et al. (1996). 


\section{Results}

As pointed out above, the effects of heterogeneity in general and inhomogeneity of a forest in particular, e.g., edges, clearings, and exposed trees, on dry deposition fluxes (e.g., Figures 3 and 4) are in the center of interest. Here, to evaluate the impact of these effects on the fluxes, synthetic landscapes of forest groups are assumed in GESIMA_EMS. The examples investigated with TreeMo-3D were selected from synthetic types of arrangements of trees in forests and groups. Furthermore, simulations are performed for a real landscape of moderate topographic complexity southeast of Berlin (Figure 2) to investigate the effect of the anthropogenic emissions released in their respective position in the explicit multi-layer subgrid on dry deposition fluxes (e.g., Figures 3 and 4). Results from SANA-field campaigns serve to examine the impact of chemical reactions on the transport process responsible for dry deposition.

\subsection{MESO- $\gamma / \beta$-SCALE MODEL}

To describe the step from a landscape to forest groups, GESIMA_EMS is applied (e.g., Friedrich et al., 2000). Three synthetic landscapes consist of patches of sandy loam covered by mixed forest and loamy soil covered by grass. They are designed in a checkerboard arrangement of forest- and grass-patches of $25 \times 25$ $\mathrm{km}^{2}$. These forest areas are sub-divided into checkerboards of $5 \times 5 \mathrm{~km}^{2}$ for the second landscape, and the latter forest areas are again sub-divided into checkerboards consisting of $1 \times 1 \mathrm{~km}^{2}$ patches for the third landscape to simulate the range from a homogeneous forest to single forest groups, i.e., the upper range of TreeMo-3D (e.g., Figure 2 in Friedrich et al., 2000). Furthermore, simulations assuming only grass or forest were carried out for comparison. The grid resolution was $5 \times 5 \mathrm{~km}^{2}$ for all 5 simulations using a $1 \times 1 \mathrm{~km}^{2}$ resolution on the subgrid.

The results of these numerical experiments suggest that the arrangement of the forest groups will non-linearly influence the fluxes if patches covered by forests exceed a certain size (e.g., Figures 3-7 in Friedrich et al., 2000). Moreover, the heterogeneity of the upwind region may play a role (see Figure 8 of these authors). Similarity coefficients calculated for the various pairs of synthetic landscapes show that the surface type dominating a landscape (e.g., forest, grass) does not necessarily determine the mean flux representative for this area. Thus, when applying the strategy of dominant surface type, i.e., ignoring the natural heterogeneity (e.g., forest edges, forest groups), the margin of error in the regional fluxes depends on the horizontal resolution of the model. Furthermore, the impact of forest patches on the turbulent flow and thus eddy fluxes seems to vary with time (see also Friedrich et al., 2000). The highest agreement between fluxes provided by the simulations with a different degree of heterogeneity is found between 12 LT (local time) and 15 LT (see Table 2 in Friedrich et al., 2000). At the boundary grass to forest, the turbulent fluxes increase. Note that this finding on the mesoscale agrees with those 
found by TreeMo-3D for the microscale (e.g., Figure 5). The increase is greater for the larger grass-forest boundaries than for the smaller ones (e.g., Figure 6).

In a further step, simulations assuming a grid resolution of $5 \times 5 \mathrm{~km}^{2}$ with (EMS5) and without (HOM5) the explicit multi-layer subgrid scheme of a horizontal resolution of $1 \times 1 \mathrm{~km}^{2}$, and with a grid resolution of $1 \times 1 \mathrm{~km}^{2}$ (HOM1) without the explicit multi-layer subgrid scheme are carried out with GESIMA_EMS for 27 July 1994 . The synoptic situation was governed by northwesterly winds carrying pollutants from Berlin into the area. Since there exist no sites to provide distributions of dry deposition fluxes, the results of the $1 \times 1 \mathrm{~km}^{2}$-simulation (HOM1) serve as a 'grand truth' to evaluate the results from the $5 \times 5 \mathrm{~km}^{2}$ simulations with and without the explicit multi-layer subgrid scheme.

Generally, the concentration distributions simulated by HOM1 and EMS5 differ only slightly (e.g., Figure 3). At noon, for instance, slight differences in the ozone concentrations can at most be found in the south-eastern part of the model domain (e.g., Figure 3). In HOM5, however, the maximum ozone concentration is too low (more than $80 \mathrm{ppb}$ ) as compared to HOM1. In HOM5, the plumes are wider than in HOM1 due to the larger extension of the grid cells. Although EMS5 has the same grid resolution of $5 \times 5 \mathrm{~km}^{2}$ like HOM5, in EMS5, the plume width is nearly the same as in HOM1 because of the use of the explicit multi-layer subgrid scheme, which has a resolution of $1 \times 1 \mathrm{~km}^{2}$ on the subgrid (e.g., Figure 3). Note that similar results are found for the other trace gases considered.

Since the concentration distributions of EMS5 and HOM1 are nearly the same (e.g., Figure 3), the distributions of dry deposition fluxes provided by EMS5 differ only slightly from those yielded by the computationally more expensive simulation HOM1 (e.g., Figure 4). Comparing the results obtained by EMS5 and HOM5 shows the great impact of subgrid-scale heterogeneity of the surface as well as of the emission sources on dry deposition fluxes (e.g., Figure 4). Sometimes behind an extended area of low vegetation, dry deposition fluxes are higher in the first subgrid cells of a forest area than in the further extend of the forest (see, e.g., Figure 4 area around $x=40 \mathrm{~km}, y=45 \mathrm{~km}$ ). This finding on the mesoscale broadly agrees with the increase of turbulent fluxes found at the forest edges in TreeMo-3D (see Subsection 3.2).

The saving in computational time by using the explicit multi-layer subgrid scheme (simulation EMS5) instead of a full finer grid resolution (simulation HOM1) non-linearly depends on model grid resolution and size, the number of subgrid points applied in the explicit multi-layer subgrid scheme, the number of hours to be simulated, the amount of trace species and reactions considered, and on the amount of processors available (see also Tetzlaff and Mölders, 1997). In the example of our study, the numerical expense due to the explicit multi-layer subgrid scheme (EMS5; i.e., subgrid refinement by a factor of 5 both in $x$ - and $y$-direction) increase by a factor of 4 as compared to the simulation with the coarse resolution (HOM5). This is about a factor 6 cheaper than the costs for the fully high-resolved 


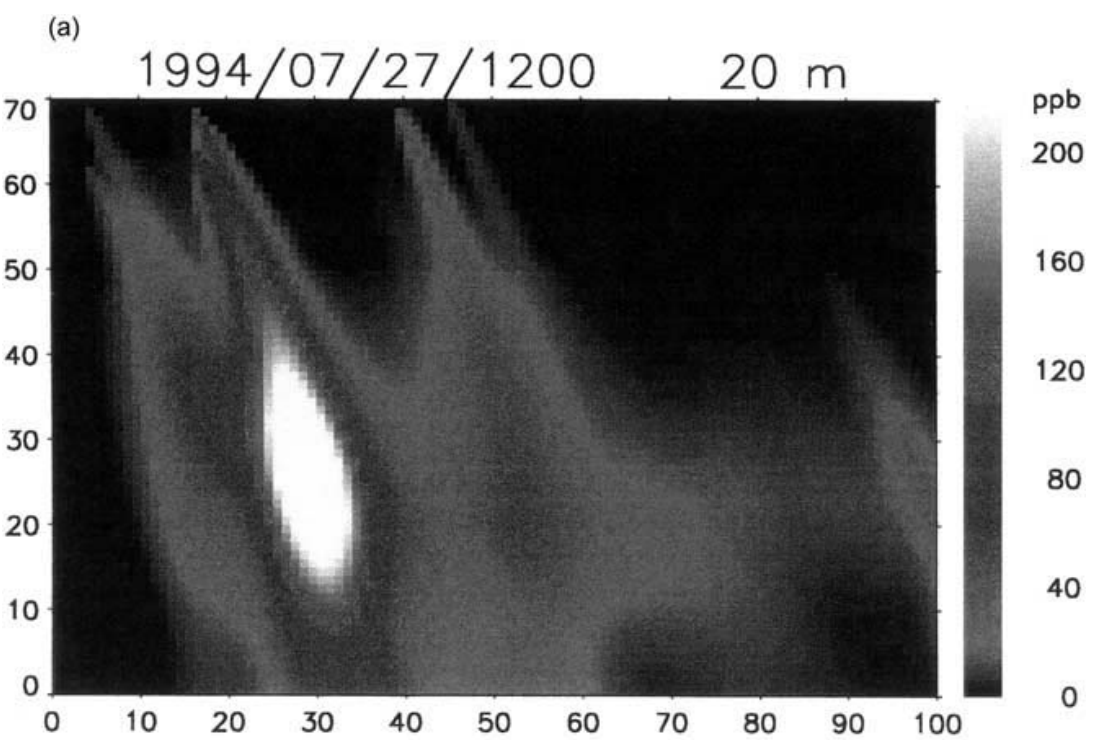

(b)

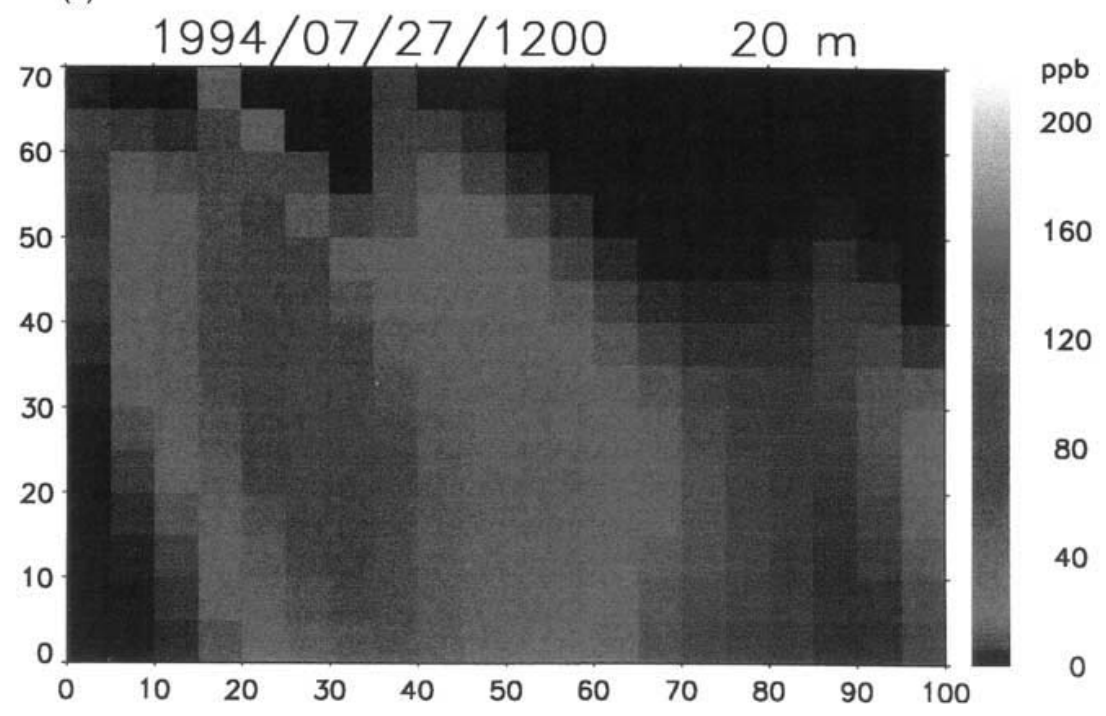

Figure 3. 


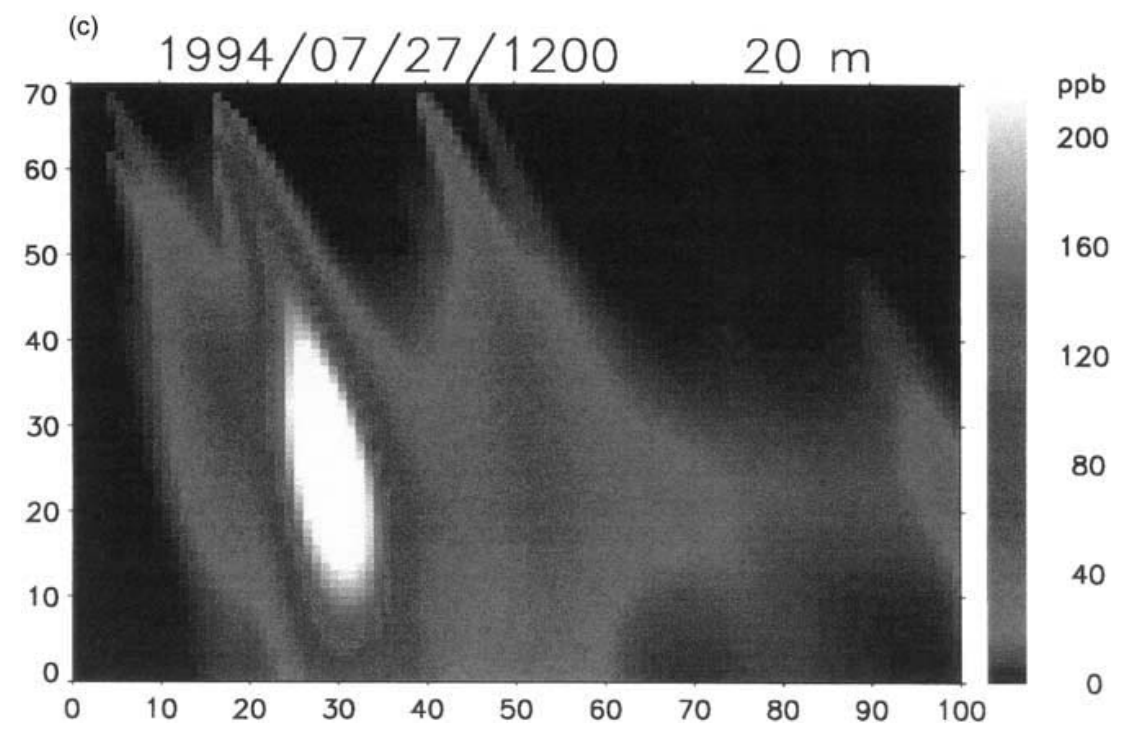

Figure 3 (continued). Distribution of ozone concentration at $1200 \mathrm{LT}$ at a height of $20 \mathrm{~m}$ above ground as simulated by (a) HOM1, (b) HOM5, and (c) EMS5. Horizontal grid extension is $100 \mathrm{~km} \times 70 \mathrm{~km}$.

simulation (HOM1) whose computational costs are about a factor of 25 higher than those of the simulation with the coarse grid resolution (HOM5).

As pointed out above, the explicit multi-layer subgrid scheme to consider subgrid scale anthropogenic and biogenic emission as well as dry deposition fluxes was developed within the framework of GESIMA. Note that the explicit multilayer subgrid-scheme meanwhile was also successfully implemented into another mesoscale model (Hinneburg et al., 2001) and provided a similar improvement as found in our study.

\subsection{MICROSCALE MODEL}

TreeMo-3D is applied to simulate the turbulent transport fluxes at and within forests and trees. In order to evaluate the effects of free standing trees, groups of trees, and forest edges on dry deposition fluxes, the results are compared to those calculated for a horizontally homogeneous forest. Note that horizontal homogeneity is the assumption for a subgrid cell or in conventional mesoscale modeling even for an entire grid cell. Thus, the following discussion provides hints on the errors remaining in mesoscale dry deposition flux modeling even when the explicit multi-layer subgrid scheme is applied, i.e., the influence of microscale effects is examined. 
(a) Ozone deposition rates on 1994/07/27/1200

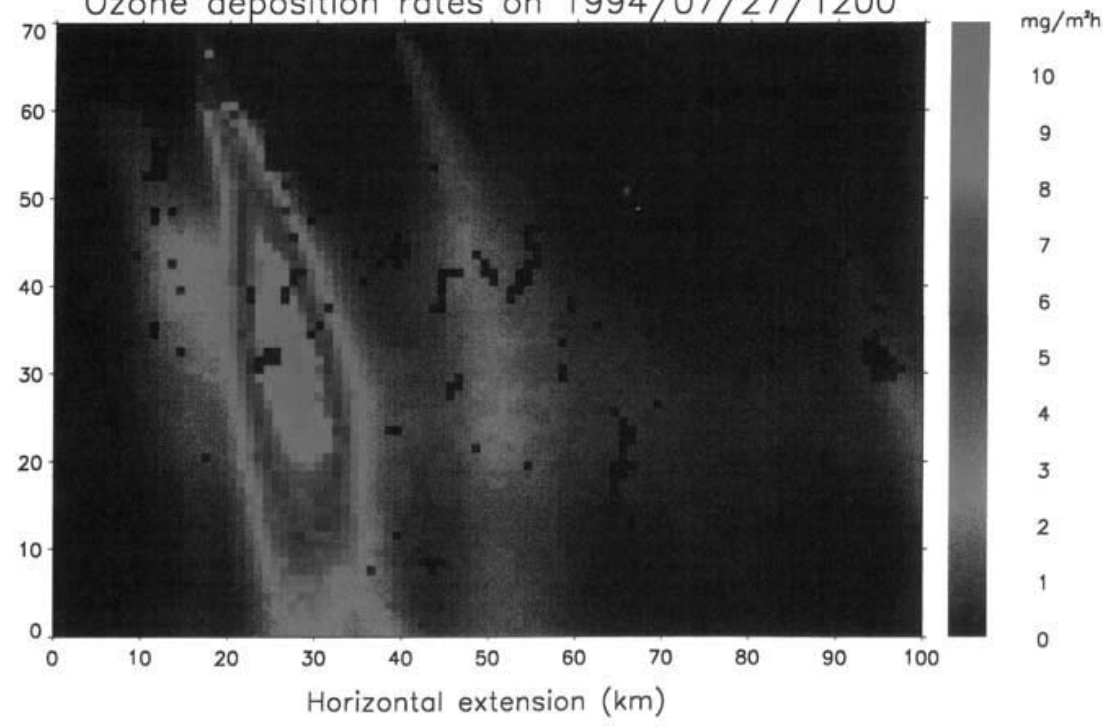

(b)

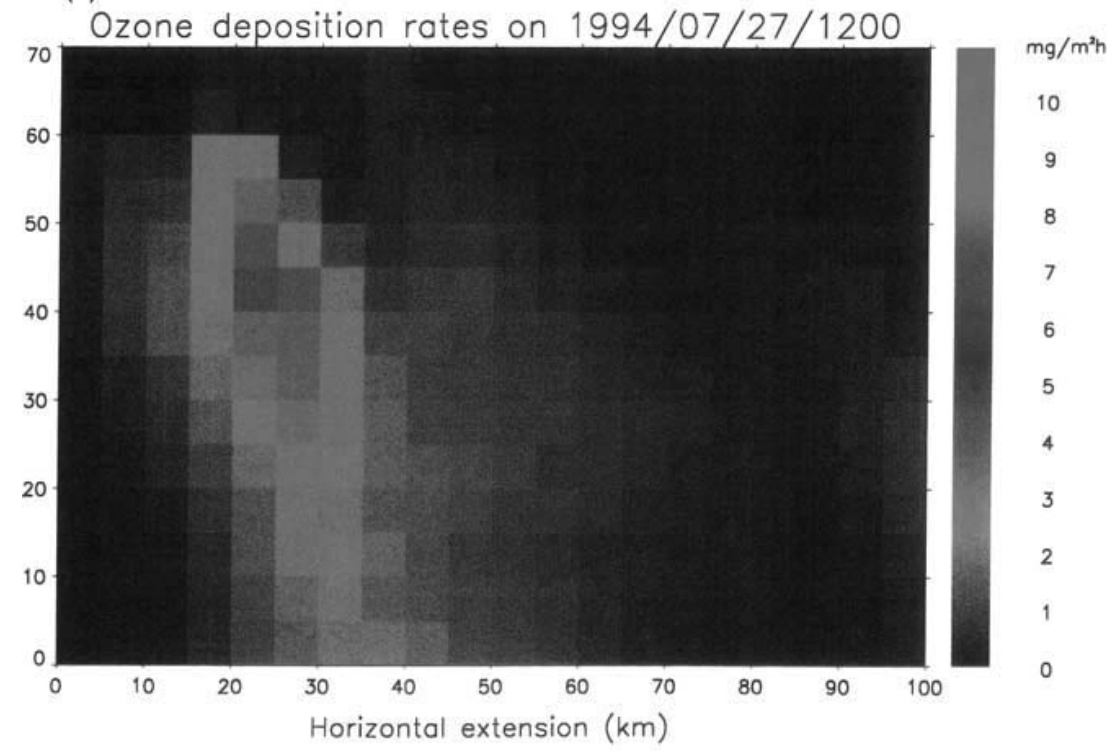

Figure 4. 
(c)

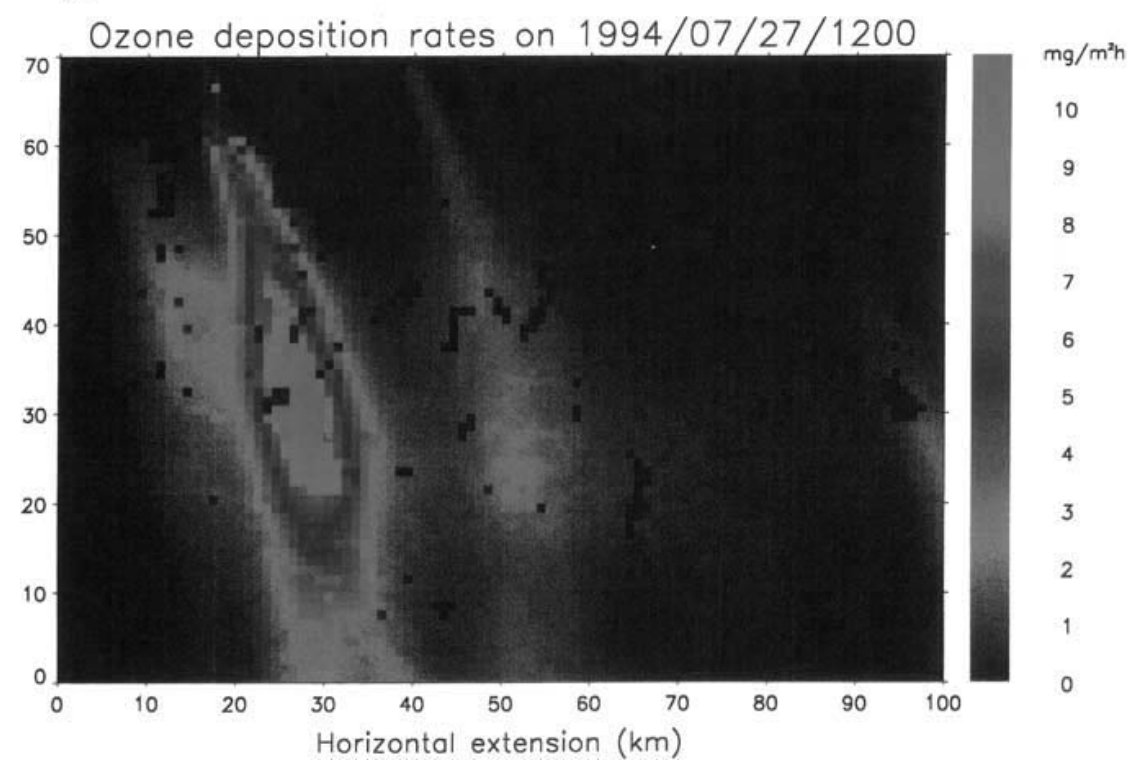

Figure 4 (continued). Distribution of dry deposition of ozone at $1200 \mathrm{LT}$ at a height of $20 \mathrm{~m}$ above ground as simulated by (a) HOM1, (b) HOM5, and (c) EMS5. Horizontal grid extension is $100 \mathrm{~km} \times 70 \mathrm{~km}$.

Prior to its application as a tool to evaluate the results provided by GESIMA_EMS, TreeMo-3D itself was evaluated by wind tunnel data (e.g., Pahl, 2000). In doing so, the results simulated by TreeMo-3D for air flow around a single tree were compared to the air flow around a tree in wind tunnel measurements (Figure 7). The comparison shows that the main features like vortices, a wake in the lee of the obstacle, and a strong underflow in the case with a stem are well reproduced by TreeMo-3D. It also captured the deposition pattern on the tree and on the surface (e.g., Figure 7).

A wide variety of numerical simulations were carried out with TreeMo-3D (e.g., Pahl, 2000). Over an area of $120 \times 50 \mathrm{~m}^{2}$ a group of 14 trees with different heights, shapes, and leaf area density were arranged and the interaction with a superimposed wind $(2 \mathrm{~m} / \mathrm{s}$ at the upper left boundary of the model domain) were studied. The mean canopy height amounts to $12.5 \mathrm{~m}$. Figure 5 demonstrates the complex air flow in a realistic stand. Comparison of vertical profiles of wind and a test tracer concentration at different, arbitrarily chosen sites (site A: $x / h=4,0, y / h=3,2$ and site $\mathrm{B}: x / h=5,0, y / h=2,0$ ), illustrates the large variability of these quantities inside the stand (Figure 8). This example emphasizes a possible application of the model in planning the location of optimal sites for field experiments in forest canopies and for a support of an interpretation of observed field date. 


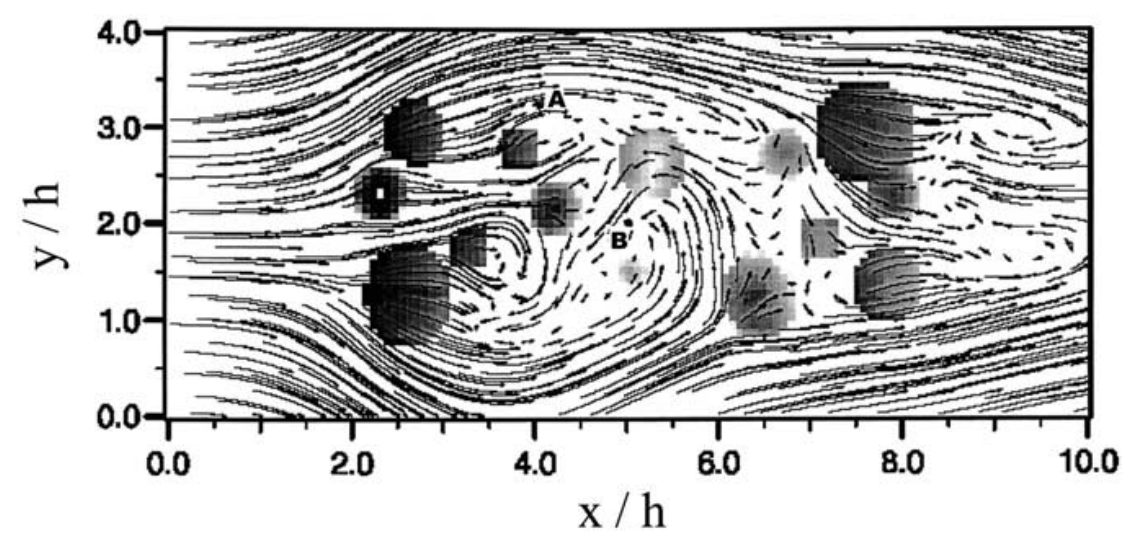

Figure 5. Wind field (arrows) in $1 \mathrm{~m}$ above ground around a group of trees (gray) with the locations of sites A and B for which the vertical profiles of a normalized test tracer concentration are shown in Figure 8. The gray levels denote to the relative deposition related to the vertical mean of the deposition onto the respective tree in the respective grid-column. Gray levels represent values from 0 (white, no deposition) to 1 (black, all gas deposited) in steps by 0.1 . Note that only deposition onto the trees not onto the ground surface is shown for clarity. At the left boundary, wind flows in at $2 \mathrm{~m} / \mathrm{s}$ at the upper boundary of the model.

Figure 5 illustrates as an example the deposition of a test tracer onto the trees at the height of the respective upper canopy-atmosphere interface. According to the results provided by TreeMo-3D, the most remarkable increase in eddy fluxes of trace species of up to a factor of 4 is found at the forest edge which results in an enhancement in dry deposition. This finding supports the increase of dry deposition fluxes simulated by EMS5 found for some subgrid cells, which are encountered initially by the air flow after passing from low vegetation to forest, to be reasonable. It has to be expected that the dry deposition fluxes determined by GESIMA_EMS may be underestimated at the low-vegetation-forest-boundary despite the use of an explicit multi-layer subgrid scheme because the resolution of the subgrid is still coarse as compared to the typical sizes of trees. As can be derived from Figure 5 the deposition fluxes vary within the forest, with the exposition of trees to the air-flow, and even on the trees themselves. In GESIMA_EMS, however, the entire subgrid cell (EMS5 or in HOM5 even the entire grid cell) is covered by a homogeneous forest without structure.

Inhomogeneity inside an extended forest also significantly modifies the dry deposition fluxes of air pollutants as compared to homogeneous conditions (e.g., Pahl, 2000). This finding broadly agrees with the results of the studies by GESIMA_EMS provided for the real and various synthetic landscapes of different degree of heterogeneity (e.g., Figures 4 and 5).

Different meteorological conditions, of course, also affect the dry deposition fluxes. The values given above are valid for an airflow perpendicular to the forest edge. By turning the oncoming wind to a parallel flow, the differences in the 
(a)

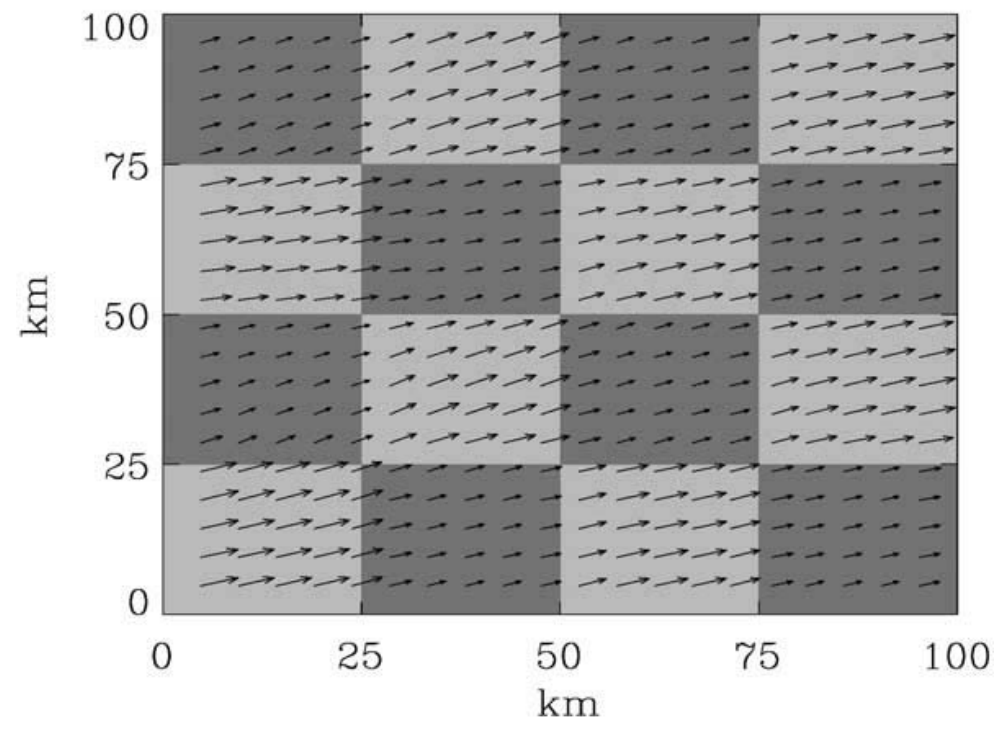

(b)

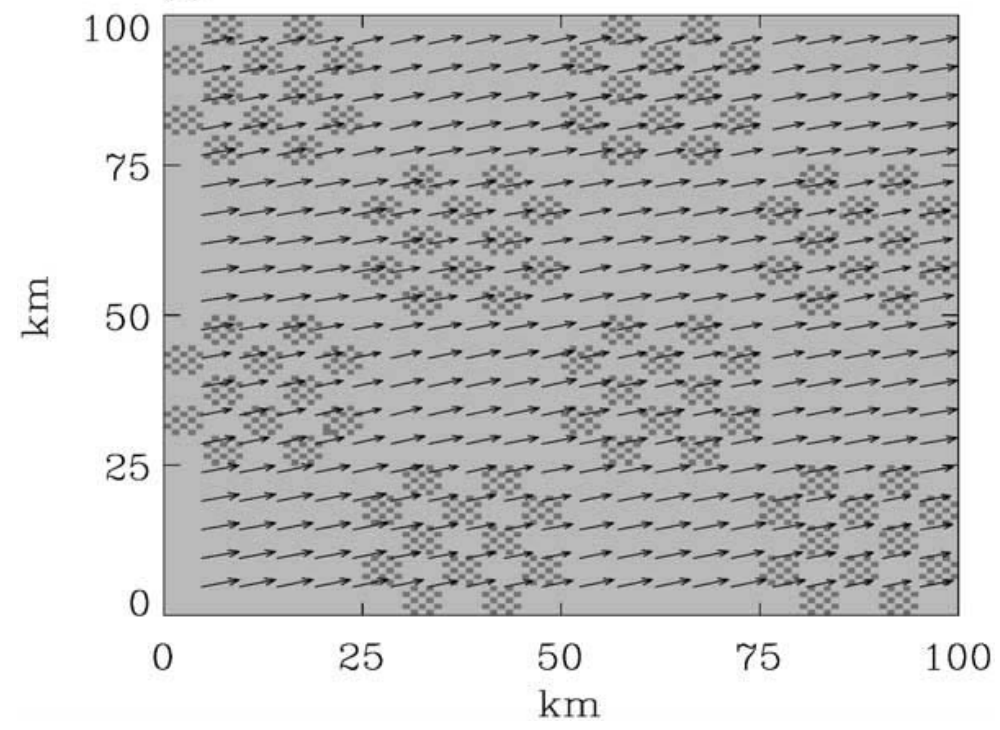

Figure 6. Horizontal wind distribution in the first level above ground for different arrangements and horizontal extensions of forest groups, (a) $25 \times 25 \mathrm{~km}^{2}$ and (b) $1 \times 1 \mathrm{~km}^{2}$ in extension. Dark gray patches indicate forest and light gray patches indicate grass. The mean windspeed amounts to about $5.4 \mathrm{~m} / \mathrm{s}$ and $2.7 \mathrm{~m} / \mathrm{s}$ above the grass- and forest-patches, respectively. Figure modified after Friedrich et al. (2000). Wind field is shown on the $5 \times 5 \mathrm{~km}^{2}$ resolution of the atmospheric grid. 
(a)

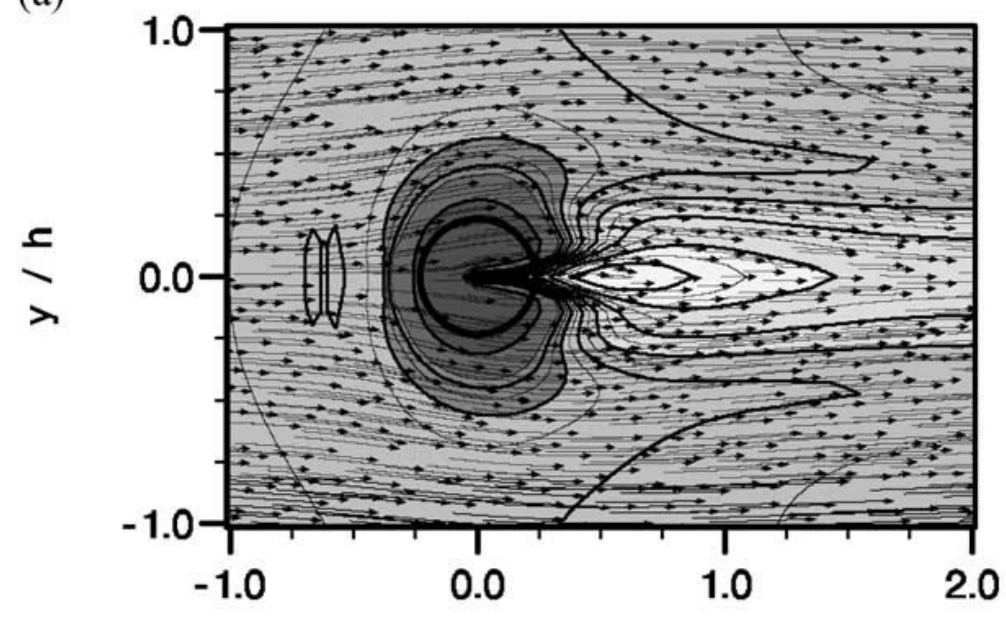

(b)

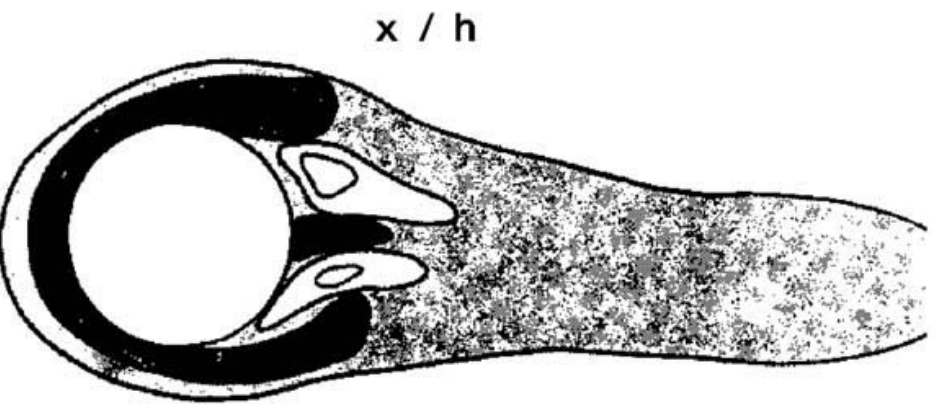

Figure 7. Comparison of dry deposition (a) as simulated by TreeMo-3D, and (b) observed in wind tunnel experiments. Air flow is superimposed as streamlines. Data from wind-tunnel experiments are taken from Ruck and Schmitt (1986). Like in Figure 5 gray levels refer to the relative deposition.

situation of a homogeneous stand become smaller than for a wind direction perpendicular to the forest edge (for more details, see Pahl, 2000). A dependence of the turbulent fluxes on the wind direction was also found by the GESIMA_EMS studies assuming various synthetic landscapes of forest and grassland (see Friedrich $e t$ $a l ., 2000)$ as well as of sand and grassland (see Friedrich and Mölders, 2000).

\subsection{IMPACT OF CHEMICAL REACTIONS AND HYDRO-THERMODYNAMIC CONDITIONS}

Here, some main features of the aforementioned SANA-experiments (Seiler $e t$ al., 1996) are re-evaluated for comparison of dry deposition fluxes over a horizontally homogeneous area covered by grass with results determined by mesoscale models, in general, and GESIMA_EMS, in particular. These measurements give hints on 


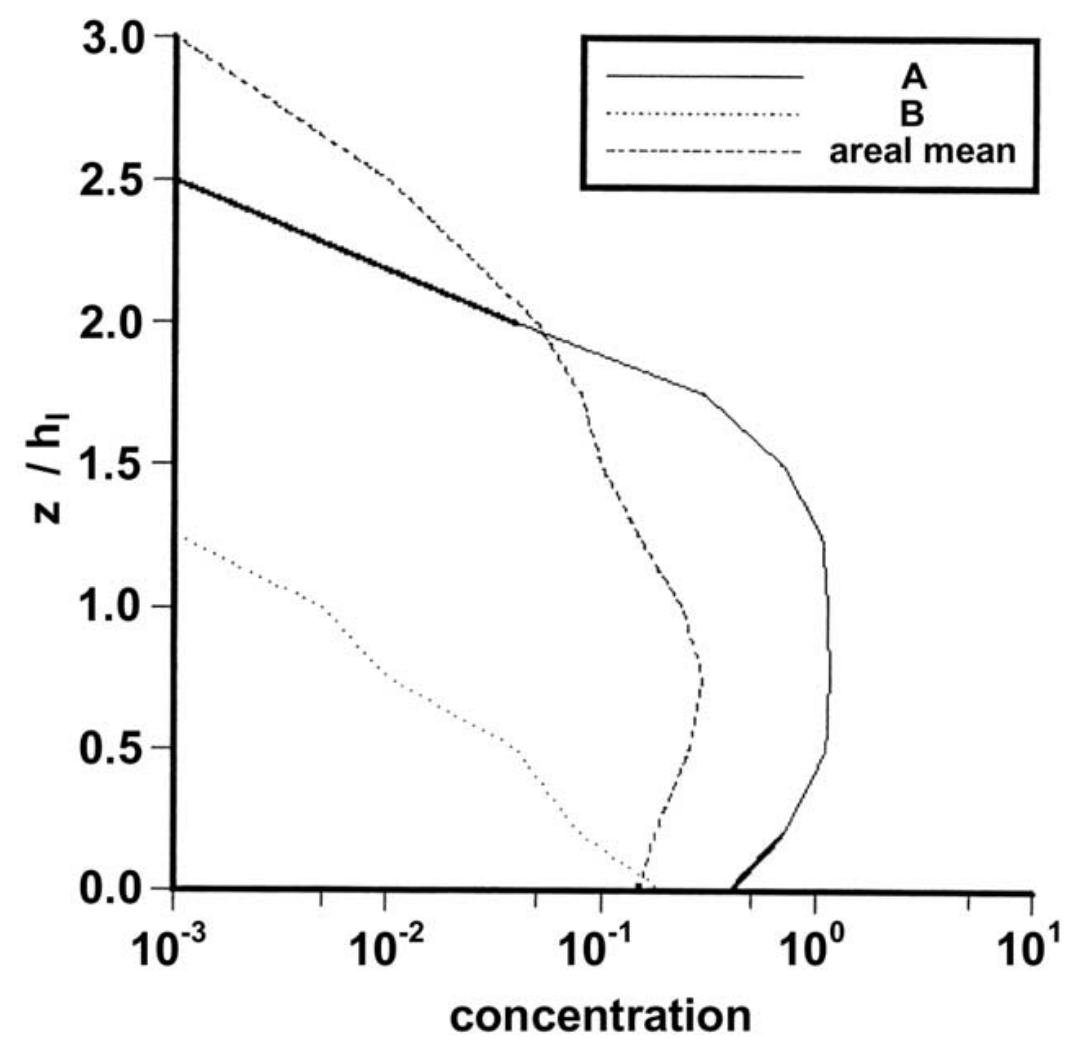

Figure 8. Vertical profiles of normalized concentration at the locations A and B indicated in Figure 5.

how to treat highly reactive trace gases in the transport processes responsible for dry deposition. This means that we evaluate the effect of the inclusion of the multilayer subgrid (in the vertical direction), which allows to take into account chemical reactions within the surface layer. Note that an overall evaluation of the horizontal subgrid by chemical measurements requires observational sites that should be arranged in groups of at least $3 \times 3$ masts with equal distance in between to catch the effects of horizontal heterogeneity and advection. Up to now such data do not exist for highly reactive trace species so that an evaluation of the horizontal subgrid can only be performed by finer resolved models and a 3D-evaluation by chemical measurements has to be postponed to the future until such data are available. But an indirect evaluation of the horizontal subgrid can be performed by looking at the various categories of hydro-thermodynamical and chemical conditions.

The following three categories of different behavior of the observed $\mathrm{HNO}_{3}$ fluxes can be distinguished: The first category of chemical behavior, on average, occurred under the thermodynamic and chemical conditions of fall 1991. For high 
nitric to ammonia ratios $\left(\mathrm{HNO}_{3} / \mathrm{NH}_{3}>3\right)$ in combination with low relative humidity and air temperatures higher than $15^{\circ} \mathrm{C}$ and above $20^{\circ} \mathrm{C}$ during late morning to late afternoon the system $\mathrm{HNO}_{3}-\mathrm{NH}_{3}-\mathrm{NH}_{4} \mathrm{NO}_{3}$-sulfat is shifted towards the gas phase and ammonium nitrate $\left(\mathrm{NH}_{4} \mathrm{NO}_{3}\right)$ will be dissociated if present. This fact is also confirmed by other authors (e.g., Kramm and Dlugi, 1994; Meng and Seinfeld, 1996; Clegg et al., 1998). $\mathrm{HNO}_{3}$ also exists in the gas phase and deposits in form of a trace gas, while $\mathrm{NO}_{3}^{-}$and $\mathrm{NH}_{4}^{+}$are in the particle phase and settle as particles. Under these conditions ammonium nitrate had typical radii of less than $1 \mu \mathrm{m}$ (see also Seidl et al., 1996). At the height of the soil-grass surface, deposition velocities of $\mathrm{HNO}_{3}$ are lower than $0.06 \mathrm{~m} / \mathrm{s}$ (cf., e.g., upper leg in Figure 9). The second category of chemical behavior mainly occurs under cooler and wetter conditions like those of fall 1993. These thermodynamic conditions favor the formation of ammonimum nitrate on sulfat- and/or carbon-dioxide-containing particles. This means that, in the atmosphere, there are sinks for $\mathrm{HNO}_{3}$ and $\mathrm{NH}_{3}$ in the presence of great amounts $\left(35-85 \mu \mathrm{g} / \mathrm{m}^{3}\right)$ of the aforementioned particles. At the height of the soil-grass surface, deposition velocities of $\mathrm{HNO}_{3}$, for example, are above $0.02 \mathrm{~m} / \mathrm{s}$ up to about $0.03 \mathrm{~m} / \mathrm{s}$ (cf., e.g., Figure 9). The third behavior occurs when there is dew in the morning lasting until the early noon. Under these conditions two concurrent sinks exist, namely, the particle phase as well as the wet grass and/or soil. If a lot of particles are present, the greatest fluxes of $\mathrm{HNO}_{3}$ are obtained with increasing mixing ratio of $\mathrm{HNO}_{3}$, because of the two sinks (see left lower leg in Figure 9). If there are only a few particles, only the wet surface serves as a sink with a resistance close to zero and a deposition velocity of $\mathrm{HNO}_{3}$ of about $0.018 \mathrm{~m} / \mathrm{s}$ to $0.03 \mathrm{~m} / \mathrm{s}$, at the height of the soil-grass surface. Under these conditions the fluxes are controlled by the transfer the viscous turbulent sublayer (leg in the center of Figure 9). Note that in the case of a great number of particles the deposition velocity of $\mathrm{HNO}_{3}$ reaches up to $0.035 \mathrm{~m} / \mathrm{s}$ to $0.04 \mathrm{~m} / \mathrm{s}$ at the height of the soilgrass surface. This different dominance of hydro-thermodynamic and chemical conditions suggests that applying an explicit subgrid in the horizontal direction as in EMS5 will improve the model results as compared to the strategy of dominant land-use and soil types for coarse grid cells like, for instance, in HOM5 because the hydro-thermodynamic and chemical conditions are more finely resolved. Note that a similar behavior as for $\mathrm{HNO}_{3}$ is found for $\mathrm{SO}_{2}$ and $\mathrm{O}_{3}$.

Ideally, a CTM should be able to represent the fluxes in the atmosphere also in the case of significant contributions of chemical reactions on trace gas fluxes in the surface layer or even the soil-vegetation system. As aforementioned, most CTMs apply the constant flux approach to determine deposition fluxes. To examine how accurate CTMs can determine these fluxes when using this approach for layers of several meters the raw data of the SANA-field campaigns were transformed into fluxes in physical units using the balance equation for chemically reactive constituents in a simplified version. In doing so, three methods are applied: (1) assume chemically conservative species (as in HOM5, HOM1 or most other CTMs), (2) estimate concentration changes due to chemical reactions from additional mea- 


\section{$\mathrm{HNO}_{3}$ Flux versus $\mathrm{HNO}_{3}$ Mixing Ratio}

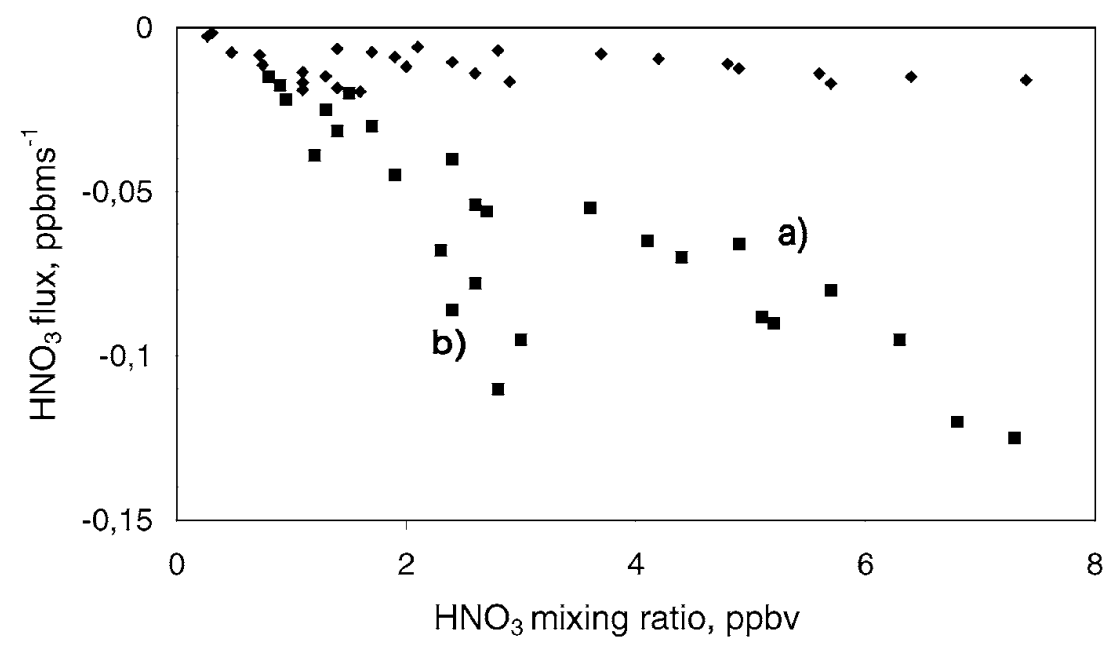

Figure 9. Fluxes of $\mathrm{HNO}_{3}$ as a function of the $\mathrm{HNO}_{3}$-mixing ratio as observed during SANA. Diamonds stand for $\left[\mathrm{HNO}_{3}\right] /\left[\mathrm{NH}_{3}\right]>3$, relative humidity lower than $65 \%$ and air temperatures greater than $18^{\circ} \mathrm{C}$, squares represent $\left[\mathrm{HNO}_{3}\right] /\left[\mathrm{NH}_{3}\right] \leqslant 1$ and (a) relative humidity lower than $80 \%$, air temperatures between $14^{\circ} \mathrm{C}$ and $18^{\circ} \mathrm{C}$, and (b) relative humidity greater equal $80 \%$, and air temperatures lower than $15^{\circ} \mathrm{C}$.

surements, specifying the conditions under which chemical reactions take place as a function of space and time (as, e.g., in Kramm and Dlugi, 1994, or EMS5), and (3) use pre-scribed deposition velocities for the various species (as, e.g., in Wesely, 1989). Note that pre-scribed species-dependent deposition velocities mean that the biological, thermodynamic, and hydrological processes are ignored. In the second method, the aerosol and trace gas measurements were analyzed by using the models of Meng and Seinfeld (1996), Seidl et al. (1996) as well as Clegg et al. (1998). The chemical reactions of trace gases are determined by a modified version of Stockwell et al.'s (1990) chemical reaction mechanism. Note that the explicit multi-layer subgrid scheme as suggested by Tetzlaff and Mölders (1997) and realized by Hinneburg and Mölders (1999, 2000) and Hinneburg (2001) considers not only the spatial resolution, but also the impact of chemical reactions within the surface layer. Namely, it calculates the chemical reactions within each subgrid cell and, hence, realizes a height-dependent profile within the first main layer above ground (i.e., within the surface layer) that is vertically divided into 10 subgrid layers. Thus, applying the explicit multi-layer subgrid scheme to calculate the concentrations corresponds to the second method (e.g., EMS5), while the first method represents the procedure customarily applied in mesoscale chemistry transport modeling (e.g., HOM5). 


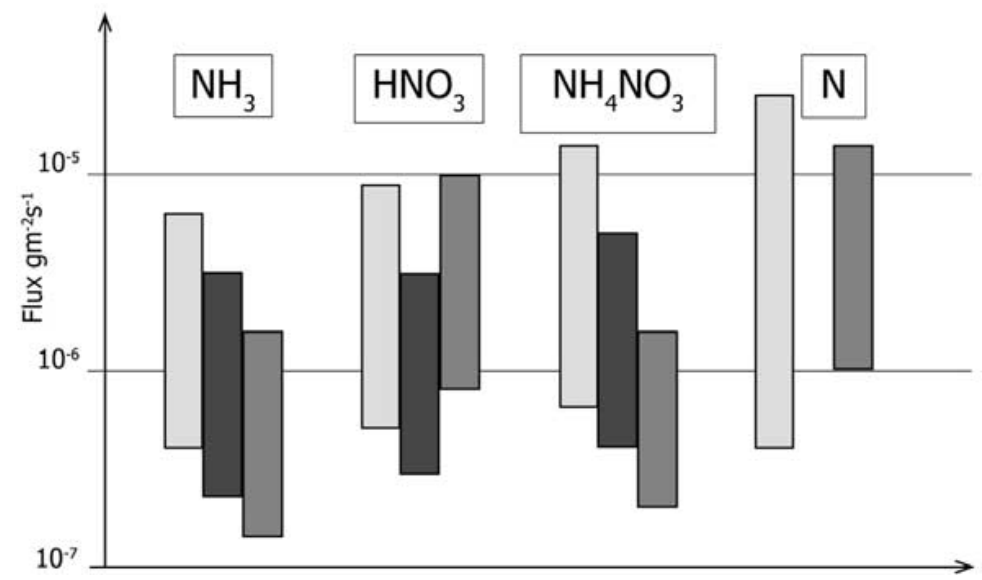

Figure 10. Daily averages of net fluxes for some nitrogen compounds and total odd nitrogen from measurements including chemical reactions (left column) and without including chemical reactions (center column) compared to results calculated assuming pre-scribed species-dependent deposition velocities (right column) for data obtained from SANA 1993.

Figure 10 illustrates for nitrogen compounds and total odd nitrogen $(\mathrm{N})$ examples of the differences between the results as obtained by the three analyzing methods. The fluxes obtained by the first method were compared to fluxes calculated directly from measured covariances or profiles to estimate the flux divergence caused by chemical reactions. Ideally, the data simulated by CTMs should match the observations. However, closer inspection reveals that for this comparison the fluxes calculated with pre-scribed species-dependent deposition velocities are virtually always smaller than those obtained by the constant flux approach for a layer of several decameters of thickness (Figure 10). The differences in the fluxes even increase when chemical reactions and emission are considered (Figure 10) as is done, for instance, by the explicit multi-layer subgrid scheme. These results suggest that ignorance of the occurrence of chemical reactions and the impact of hydrological, biological and thermodynamic processes may lead to an underestimation of the deposition fluxes. Thus, based on these findings we may conclude that the inclusion of the explicit multi-layer subgrid scheme is a step forward to better catch the impact of hydrological, biological and thermodynamic processes and, hence, dry deposition and emission fluxes. However, it has to be expected that there will still be a discrepancy because of uncertainties in the description of the hydrologic status of the soil-vegetation system, and neglecting the intensity of segregation. This means that, in chemistry transport modeling, improved results can only be achieved when the conventional constant flux approximation is not applied for layers of several decameters. Instead, these models have to be adjusted to allow the chemical reaction taking place during transport to the surface as is realized by the explicit multi-layer subgrid scheme. 


\section{Conclusions}

Generally, results of field campaigns do not allow quantitative description of how the eddy fluxes of trace species in the near-surface layer and, hence, the respective dry deposition processes are affected: (1) by horizontally inhomogeneous distributions of vegetation, and anthropogenic as well as biogenic emission sources of trace species, and (2) by chemical reactions. The processes that contribute to the observed concentrations or meteorological quantities cannot be derived from the concentrations or quantities themselves. Thus, to explain the observed values models are required. Consequently, numerical models have to be developed to support the interpretation of field measurements by computer simulations. In doing so, an explicit multi-layer subgrid scheme was developed and established in GESIMA to describe the subgrid scale surface heterogeneity, heterogeneity of anthropogenic and biogenic emission as well as dry deposition fluxes and chemical reactions closer to their natural equivalent than usually done in conventional CTMs. Since concurrent field measurements of first moments, like the mean values of trace gas concentrations, wind speed, temperature, and humidity, and second moments like eddy fluxes of trace species, momentum, sensible heat, and water vapor, as well as corresponding variances are still scarce or unavailable, the basis for an evaluation of parameterization approaches like an explicit multi-layer subgrid scheme is meager. To get a step further in scientific progress despite of this barrier, a concept was designed to evaluate the explicit multi-layer subgrid scheme by considering heuristic principles, where (1) results from simulations with the same model for a grid resolution much finer as customarily used in conventional CTMs performed for natural and artificial surface heterogeneity as well as (2) those provided by the evaluated microscale model TreeMo-3D and (3) some reliable measurements serve as an expedient.

The model results as well as the dry deposition fluxes derived from observations evidence that parameterization approaches like the explicit multi-layer subgrid scheme presented here are a step forward to a closer to nature description of dry deposition, biogenic and anthropogenic emission behavior in modeling dynamicchemical processes on the mesoscale. The measurements suggest that the inclusion of the multi-layer subgrid improves the results as compared to the commonly applied constant flux approach for a layer of several decameters. Comparing of the results from the mesoscale model with and without the explicit multi-layer subgrid scheme with the results from the mesoscale model with fine resolution or the microscale model shows that the explicit multi-layer subgrid scheme improves the description of the horizontal variation of the dry deposition fluxes.

The results from the studies with artificial landscapes of different degrees of heterogeneity, and distribution of forest groups show that when applying the strategy of dominant land-use type, the margin of error in the regional fluxes depends on the horizontal resolution of the model. The results from zooming into the forest groups give evidence for significant modification of the eddy fluxes of trace species, and, 
hence, of dry deposition processes. The most remarkable increase in these eddy fluxes amounts to up to a factor of 4 at the forest edges. Consequently, mesoscale models will probably underestimate dry deposition at the boundary between low and high vegetation and vice versa even if an explicit multi-layer subgrid scheme is applied. It is worth mentioning that the microscale effects of the edges of a forest will amount only to a few percent if there are no further edges within the subgrid cells in EMS5.

The accuracy of all branches within the cycle of a trace constituent is governed by the branch with the least accuracy. Consequently, it has to be suspected that in most cases dry deposition is the weakest link in the chain of emissiontransport-transformation-deposition because in the near-surface layer the transfer and transformation of trace species is strongly affected by the energy and water cycles. These cycles, of course, are governed by the surface properties. Since one is interested in determining the input of trace species into sensitive ecosystems, considerable efforts to improve our understanding of the processes governing dry deposition are justified. The scarcity of complete and quality controlled field data which can be used for an evaluation and their limitation to few cases underlines the shortcomings. Nevertheless, the outlined approach yielded some improvements for modeling dry deposition processes. A final evaluation of the model results has to be postponed until concurrent measurements, at least, of first and second moments of all quantities involved in dynamic-chemical processes are available with sufficient spatial and temporal resolution. Since the results of TreeMo-3D showed that the distribution of these quantities may vary strongly within the canopy, the locations of measuring sites have to be chosen carefully.

Based on our findings that even with consideration of horizontally inhomogeneous distributions of vegetation as well as anthropogenic and biogenic emission sources of trace species and chemical reactions in the prediction of dry deposition processes as done by the explicit multi-layer subgrid scheme simulated dry deposition fluxes may be underestimated, may be a hint that higher moments are of great importance and have to be included in future. Consequently, canopy turbulence models of, at least, higher than one-and-a-half-order closure that are able to predict segregation effects have to be developed.

A rigorous evaluation of the explicit multi-layer subgrid scheme and the simulations of CTMs requires data-sets of anthropogenic emissions, air constituents and meteorological quantities as well as water-, energy- and trace gas fluxes in a high quality, spatial and temporal resolution for the region under study. The available data-sets are not yet ready to fulfil this objective. To improve the possibility to evaluate CTMs, measurements of segregation effects (e.g., Kramm and Meixner, 2000) are an urgent need. In addition, to catch the effects of heterogeneity observational sites should be arranged in groups of at least $3 \times 3$ masts with equal distance in between. This group of mast should be installed so that they cover a boundary of different land-use. Until such data-sets are available we can only try to evaluate simulated dry deposition fluxes as performed in our study, namely, 
by using a combination of available measurements, more detailed simulations, for instance, by higher resolved models or models which have been evaluated by different independent data.

\section{Acknowledgements}

This work was funded within the framework of the Tropospheric Research Program (TFS) by the German Ministry for Education, Technology, and Research (BMBF) under contracts LT2.D.2, LT2.D.3, and LT1.B.6, respectively. It was also partially supported through DFG grant, Mo770/2-1. We wish to express our thanks to G. Kramm (University Alaska Fairbanks) and K. E. Erdmann (emc Leipzig) and the anonymous reviewers for fruitful discussion and helpful comments. Our thanks are also given to B. Smiatek (IFU Garmisch-Partenkirchen) for providing land-use data and W. Wickert (IER Stuttgart) for the anthropogenic emission data.

\section{References}

Arya, S. P., 1988: Introduction to Micrometeorology, Academic Press, San Diego, p. 303.

Avissar, R. and Pielke, R. A., 1989: A parameterization of heterogeneous land surface for atmospheric numerical models and its impact on regional meteorology, Mon. Wea. Rev. 117, 2113-2136.

Baer, M. and Nester, K., 1992: Parameterization of trace gas dry deposition velocities for a regional mesoscale diffusion model, Ann. Geophys. 10, 912-923.

Baldocchi, D. D., 1988: A multi-layer model for estimating sulfur dioxide deposition to a deciduous oak forest canopy, Atmos. Environ. 22, 869-884.

Beier, N., Schroers, H., Müller, D., and Weber, M., 1997: Grenzschichtmeteorologische Untersuchungen zur trockenen Deposition chemisch inerter und reaktiver Luftbeimengungen, BMBF-Abschlussbericht, Meteorol. Inst. München.

Blackadar, A. K., 1962: The vertical distribution of wind and turbulent exchange in a neutral atmosphere, J. Geophys. Res. 67, 3095-3103.

Bowling, D. R., Delany, A. C., Turnispeed, A. A., Baldocchi, D. D., and Mason, R.K., 1999: Modification of the relaxed eddy accumulation technique to maximize the measured scalar mixing ratio differences in updrafts and downdrafts, J. Geophys. Res. 104D, 9121-9133.

Brost, R. A., Delany, A. C., and Huebert, B. J., 1988: Numerical modeling of concentrations and fluxes of $\mathrm{HNO}_{3}, \mathrm{NH}_{3}$, and $\mathrm{NH}_{4} \mathrm{NO}_{3}$ near the surface, J. Geophys. Res. 93, 7137-7152.

Brunnemann, G., Kins, L., and Dlugi, R., 1996: Physical and chemical characterisation of the atmospheric aerosol: An overview of the measurements during SANA2 campaign at Melpitz, Meteorol. Zeitschr. 5, 245-256.

Businger, J. A., Wyngaard, J. C., Izumi, Y., and Bradley, E. F., 1971: Flux profile relationship in the atmospheric surface layer, J. Atmos. Sci. 28, 181-189.

Businger, J. A., 1986: Evaluation of the accuracy with which dry deposition can be measured with current micrometeorological techniques, J. Appl. Meteorol. 25, 1100-1124.

Chang, J. S., Brost, R. A., Isaksen, I. S. A., Madronich, S., Middleton, P., Stockwell, W. R., and Walcek, C. J. 1987: A three dimensional Eulerian acid deposition model: physical concepts and formulation, J. Geophys. Res. 92, 14681-14700.

Clegg, S. L., Brimblecombe, P., and Wexler, A. S., 1998: Thermodynamic model of the system $\mathrm{H}^{+}-\mathrm{NH}_{4}^{+}-\mathrm{SO}_{4}^{2-}-\mathrm{NO}_{3}^{-}-\mathrm{H}_{2} \mathrm{O}$ at tropospheric temperatures, J. Phys. Chem. A102, 2147-2165. 
Deardorff, J. W., 1978: Efficient prediction of ground surface temperature and moisture with inclusion of a layer of vegetation, J. Geophys. Res. 8(3), 1889-1903.

Dlugi, R., 1988: Deposition of gaseous and particulate compounds from a profile method, in H. van Dop (ed.), Air Pollution Modelling and its Application, VI. Plenum, pp. 49-60.

Dlugi, R., 1993: Interaction of $\mathrm{NO}_{x}$ and VOCs within vegetation, in P. M. Borrell, P. Borrell, T. Cvitas, and W. Seiler (eds), Photo-Oxidants: Precursors and Products, Proceedings of EUROTRAC Symposium '92, Academic Publishing, The Hague, pp. 682-688.

Ebel, A., Hass, H., Jakobs, H. J., Laube, M., and Mölders, N., 1994: Simulation of chemical transformation and vertical redistribution of air pollutants in clouds, in Physico-Chemical Behaviour of Atmospheric Pollutants, Proceedings of the Sixth European Symposium, Varese, 18-22 October, pp. 1035-1039.

Eppel, D. P., Kapitza, H., Claussen, M., Jacob, D., Koch, W., Levkov, L., Mengelkamp, H.-T., and Werrmann, N., 1995: The non-hydrostatic mesoscale model GESIMA. Part II: Parameterizations and applications, Contrib. Atmos. Phys. 68, 15-41.

Falls, A. H. and Seinfeld, J. H., 1978: Continued development of kinetic mechanism for photochemical smog, Environ Sci. Technol. 12, 1398-1406.

Feldmann, H., Hass, H., Memmesheimer, M., and Jakobs, H.-J., 1996: Budgets of atmospheric sulfur for East Germany based on meso- $\alpha$-scale simulations, Meteorol. Zeitsch. 5, 194-204.

Fitzjarrald, D. R., and Lenschow, D. H., 1983: Mean concentration and flux profiles for chemically reactive species in the atmospheric surface layer, Atmos. Environ. 17, 2505-2512.

Friedrich, K., Mölders, N., and Tetzlaff, G., 2000: On the influence of surface heterogeneity on the Bowen-ratio: A theoretical case study, Theor. Appl. Clim. 65, 181-196.

Friedrich, K. and Mölders, N., 2000: On the influence of surface heterogeneity on latent heat-fluxes and stratus properties. Atmos. Res. 54, 59-85.

Ganzeveld, L. and Lelieveld, J., 1995: Dry deposition parameterization in a chemistry general circulation model and its influence on the distribution of reactive trace gases, J. Geophys. Res. 100D, 1999-2001.

Gao, W., Wesely, M. L., and Lee, I. Y., 1991: A numerical study of the effects of air chemistry on fluxes of $\mathrm{NO}, \mathrm{NO}_{2}$, and $\mathrm{O}_{3}$ near the surface, J. Geophys. Res. 96D, 18761-18769.

Gross, G., 1993: Numerical Simulations of Canopy Flows, Springer, Berlin.

Hanson, P. J. and Lindberg, S. E., 1991: Dry deposition of reactive nitrogen componds: A review of leaf, canopy and non-foliar measurements, Atmos. Environ. 25A, 1615-1634.

Hass, H., Jacobs, H. J., and Memmesheimer, M., 1995: Analysis of a regional model (EURAD) nearsurface gas concentration predictions using observations from networks, Meteorol. Atmos. Phys. 57, 173-200.

Hicks, B. B., Baldocchi, D. D., Meyers, T. P., Hosker, J. R. P., and Matt, D. R., 1987: Preliminary multiple resistance routine for deriving dry deposition velocities from measured quantities, Water Air Soil Pollut. 36, 311-330.

Hinneburg, D. and Mölders, N., 1999: A mesoscale atmospheric model combining meteorology, chemistry, biology and heterogeneity, in A. Raabe, K. Arnold, and J. Heintzenberg (eds), Meteorologische Arbeiten aus Leipzig (IV), Wiss. Mitt. Leipzig 12, pp. 44-58.

Hinneburg, D. and Mölders, N., 2000: Dry deposition by an atmospheric model with horizontal subgrid, in K. Arnold and A. Raabe (eds), Meteorologische Arbeiten aus Leipzig (V), Wiss. Mitt. Leipzig 17, pp. 18-28.

Hinneburg, D., 2001: A mesoscale atmospheric model with horizontal subgrid for chemical transport, Phys. Chem. Earth 26, 111-115.

Hinneburg, D., Knoth, O., Mölders, N., Münzenberg, A., and Wolke, R., 2001: Subgrid-modelling of dry deposition, in W. Seiler et al. (eds), The Proceedings of the EUROTRAC Symposium 2000, VITpress, Southampton, in press. 
Inclan, M., Forkel, R., Dlugi, R., and Stull, R., 1996: Application of transilient turbulent theory to study interactions between the atmospheric boundary layer and forest canopies, Boundary-Layer Meteorol. 79, 315-344.

Inoue, K., 1963: On the turbulent structure of airflow within crop canopies, J. Meteor. Soc. Jap. 11, $18-22$.

John, C., 1999: Emissionen von Luftverunreinigungen aus dem Straßenverkehr in hoher räumlicher und zeitlicher Auflösung - Untersuchungen von Emissionsszenarien am Beispiel BadenWürtembergs, IER Research Reports, Ph.D. thesis, p. 214, in German.

Kapitza, H. and Eppel, D. P., 1992: The non-hydrostatic mesoscale model GESIMA. Part I: Dynamical equations and tests. Contr. Phys. Atmos. 65, 129-146.

Kramm, G., 1989: A numerical model to determine dry deposition of atmospheric trace gases, Boundary-Layer Meteorol. 48, 157-176.

Kramm, G. and Dlugi, R., 1994: Modelling of the vertical fluxes of nitric acid, ammonia, and ammonium nitrate, J. Atmos. Chem. 18, 319-357.

Kramm, G., Dlugi, R., Mölders, N., and Müller, H., 1994: Numerical investigations of the dry deposition of reactive trace gases, in J. M. Baldasano, C. A. Brebbia, H. Power, and P. Zannetti (eds), Air Pollution II Vol. 1: Computer Simulation, Computational Mechanics Publications, Southampton, Boston, pp. 285-307.

Kramm, G., 1995: Zum Austausch von Ozon und reaktiven Stickstoffverbindungen zwischen Atmosphäre und Biosphäre, Wissenschafts-Verlag Dr. W. Maraun, Frankfurt/Main, Germany.

Kramm, G., Dlugi, R., Dollard, G. J., Foken, T., Mölders, N., Müller, H., Seiler, W., and Sievering, H.: 1995, On the dry deposition of ozone and reactive nitrogen compounds, Atmos. Environ. 29, 3209-3231.

Kramm, G. and Mölders, N., 1996: Investigations on the exchange of water and reactive trace constituents under consideration of various aspects of heterogeneity, in P. M. Borrell, P. Borrell, T. Cvitas, K. Kelly, and W. Seiler (eds.), The Proceedings of the EUROTRAC Symposium '96, Computational Mechanics Publications, Southampton, pp. 79-84.

Kramm, G., Beier, N., Foken, T., Müller, H., Schröder, P., and Seiler, W., 1996: A SVAT scheme for $\mathrm{NO}, \mathrm{NO}_{2}$, and $\mathrm{O}_{3}-$ model description. Meteorol. Atmos. Phys. 61, 89-106.

Kramm, G., Beier, N., Dlugi, R., and Müller, H., 1999: Evaluation of conditional sampling methods, Contrib. Atmos. Phys. 72, 161-172.

Kramm, G. and Meixner, F. X., 2000: On the dispersion of trace species in the atmospheric boundary layer: A re-formulation of the governing equations for the turbulent flow of the compressible atmosphere. Tellus 52A, 500-522.

Kumar, N., Odman, M. T., and Russell, A. G., 1994: Multiscale air quality modeling: Application to southern California, J. Geophys. Res. 99, 5385-5397.

Lenschow, D. H. and Delany, A. C., 1987: Dry deposition of nitrogen-containing species, Atmos. Environ. 30, 2889-2900.

Mahrt, L., Lenschow, D. H., Sun, J., and Weil, J. C., 1995: Ozone fluxes over patchy cultivated surface, J. Geophys. Res. 100D, 23125-23131.

McRae, G. J. and Seinfeld, J. H., 1983: Development of a second-generation mathematical model for urban pollution I. Model formulation, Atmos. Environ. 16, 679-696.

McRae, G. J. and Russell, A. G., 1984: Dry deposition of nitrogen-containing species, in B. B. Hicks (ed.), Deposition Both Wet and Dry, Acid Precipitation Series Vol. 4. Butterworth, Boston/London, pp. 153-193.

Mellor, G. L. and Yamada, T., 1974: A hierarchy of turbulence closure models for planetary boundary layers, J. Atmos. Sci. 31, 1791-1806.

Meng, Z. and Seinfeld, J. H., 1996: Time scales to achieve atmospheric trace gas aerosol equilibrium for voltile species, Atmos. Environ. 30, 2889-2900.

Meyers, T. and Paw U, K. T., 1986: Testing of a higher-order closure model for modeling airflow within and above plant canopies, Boundary-Layer Meteorol. 37, 297-311. 
Meyers, T. P. and Paw U, K. T., 1987: Modelling the plant canopy micrometeorology with higherorder closure principles, Agric. Forest Meteorol. 41, 143-163.

Meyers, T. P. and Baldocchi, D. D., 1988: A comparison of models for deriving dry deposition fluxes of $\mathrm{O}_{3}$ and $\mathrm{SO}_{2}$ to a forest canopy, Tellus 40B, 270-284.

Mölders, N., Raabe, A., and Tetzlaff, G., 1996: A comparison of two strategies on land surface heterogeneity used in a mesoscale $\beta$ meteorological model, Tellus 48A, 733-749.

Mölders, N., Kramm, G., Laube, M., and Raabe, A., 1997: On the influence of bulk-parameterization schemes of cloud microphysics on the predicted water-cycle relevant quantities - a case study, Meteorol. Zeitschr. 6, 21-32.

Mölders, N., 1998: Landscape changes over a region in East Germany and their impact upon the processes of its atmospheric water-cycle, Meteorol. Atmos. Phys. 68, 79-98.

Müller, H., Kramm, G., Meixner, F. X., Fowler, D., Dollard, G. J., and Possanzani, M., 1993: Determination of $\mathrm{HNO}_{3}$ dry deposition by modified Bowen ratio and aerodynamic profile techniques, Tellus 45B, 346-367.

Müller, T., 1994: Ermittlung der $\mathrm{SO}_{2}$ - und $\mathrm{NO}_{x}$-Emissionen aus stationären Feuerungsanalgen in Baden-Würtemberg in zeitlicher Auflösung, IER Research Reports, Ph.D. thesis, p. 142, in German.

Obermeier, A., 1995: Ermittlung und Analyse von Emissionen flüchtiger organischer Verbindungen in Baden-Würtemberg, IER Research Reports, Ph.D. thesis, p. 208, in German.

Oncley, S. P., Delany, A. C., Horst, T. W., and Trans, P., 1993: Verification of flux measurements using relaxed eddy accumulation, Atmos. Technol. A27, 2417-2426.

Orlanski, I., 1975: A rational subdivision of scales for atmospheric processes, Bull. Amer. Meteorol. Soc. 56, 527-530.

Orlanski, I., 1976: A simple boundary condition for unbounded hyperbolic flows, J. Comp. Phys. 21, 251-269.

Padro, J., Zhang, L., Massman, W. J., and Stocker, D. W., 1995: An application of a dry deposition model including the chemical reactions of $\mathrm{NO}-\mathrm{NO}_{2}-\mathrm{O}_{3}$, in $\mathrm{H}$. Power, N. Moussiopoulos, C. A. Bredia (eds), Air Pollution III: Engineering and Management, Computational Mechanics Publication, Southhampton, Boston, pp. 93-100.

Pahl, U., 2000: Numerische Simulationen zum Einfluß von Waldbestandsinhomogenitäten auf die Windverhältnisse und die trockene Spurenstoffdeposition, Ber. Inst. Met. Klim. Univ. Hannover 25, Ph.D. thesis, p. 100.

Pleim, J. E., Chang, J. S., and Zhang, K., 1991: A nested grid mesoscale atmospheric chemistry model, J. Geophys. Res. 96, 3065-3084.

Rinne, H. J. I., Delany, A. C., Greenberg, J. P., and Guenther, A. B., 2000: A true eddy accumulation system for trace gas fluxes, J. Geophys. Res. 105, 24791-24798.

Ruck, B. and Schmitt, F., 1986: Das Strömungsfeld der Einzelbaumumströmung, Forstwiss. Centralbl. 105, 178-196.

Seidl, W., Brunnemann, G., Kins, L., Köhler, E., Reußwig, K., and Dlugi, R., 1996: On the composition of aerosol particles and related gas phase species at two sites during SANA2 campaign at Melpitz. Meteorol. Zeitschr. 5, 257-268.

Seinfeld, J. H., 1986: Atmospheric Chemistry and Physics of Air Pollution, Wiley, New York/ Chichester/Brisbane/Toronto/Singapore, p. 738.

Seiler, T., Reuder, J., Beyrich, F., and Feldmann, H., 1996: Meteorological conditions during SANA1 (Eisdorf) and SANA2 (Melpitz), Meteorol. Zeitschr. 5, 181-193.

Seth, A., Giorgi, F., and Dickinson, R. E., 1994: Simulating fluxes from heterogeneous land surfaces: explicit subgrid method employing the biosphere-atmosphere transfer scheme (BATS), $J$. Geophys. Res. 99D, 18651-18667.

Slemr, F. and Seiler, W., 1984: Field measurements of $\mathrm{NO}$ and $\mathrm{NO}_{2}$ emissions from fertilized and unfertilized soils, J. Atmos. Chem. 2, 1-14. 
Shaw, R. H. and Schumann, U., 1992: Large-eddy simulation of turbulent flow above and within a forest, Boundary-Layer Meteorol. 61, 47-64.

Smolarkiewicz, P. K., 1984: A fully multidimensional positive definite advection transport algorithm with small implicit diffusion, J. Comp. Phys. 54, 325-362.

Smolarkiewicz, P. K. and Clark, T. L., 1986: The multidimensional positive definite advection transport algorithm: Further development and applications. J. Comp. Phys. 67, 396-438.

Spindler, G., Mölders, N., Hansz, J., Beier, N., and Kramm, G., 1996: Determining the dry deposition of $\mathrm{SO}_{2}, \mathrm{O}_{3}, \mathrm{NO}$, and $\mathrm{NO}_{2}$ at the SANA core station Melpitz, Meteorol. Zeitschr. 5, 205-220.

Stockwell, W. R., Middleton, P., Chang, J. S., and Tang, X., 1990: The second generation regional acid deposition model, chemical mechanism for regional air quality modeling, J. Geophys. Res. 95, 16343-16367.

Tetzlaff, G. and Mölders. N., 1997: Beurteilung der Modellierbarkeit des flächenbezogenen Eintrages von Spurenstoffen durch Deposition, in W. v. Hoyningne-Huene and G. Tetzlaff (eds), Sediment und Aerosol, Wiss. Mitt. Leipzig, 6, 99-144.

Trepte, S., 1998: Simulation innerstädtischer Konzentrationsfelder mit einem mikroskaligen ChemieTransport-Modell, Shaker Verlag, Aachen, p. 111, in German.

Walcek, C. J., Brost, R. A., and Chang, J. S., 1986: $\mathrm{SO}_{2}$, sulfat and $\mathrm{HNO}_{3}$ deposition velocities computed using regional landuse and meteorological data, Atmos. Environ. 20, 949-964.

Wesely, M. L., 1989: Parameterization of surface resitances to gaseous dry deposition in regionalscale numerical models, Atmos. Environ. 23, 1293-1304.

Venkatram, A., Karamchanddani, P. K., and Misra, P. K., 1988: Testing a comprehensive acid deposition model, Atmos. Environ. 22, 737-747.

Vogel, B., Fiedler, F., and Vogel, H., 1995: Influence of topography and biogenic voltaile organic compounds emission in the state of Baden-Würtemberg on ozone concentrations during episodes of high air temperature, J. Geophys. Res. 100, 22907-22928.

Yamada, T., 1982: A numerical study of turbulent airflow in and above a forest canopy, J. Meteorol. Soc. Jap. 60, 439-454.

Ziemann, A., 1998: Numerical simulations of meteorological quantities in and above forest canopies, Meteorol. Zeitsch. 7, 120-128. 